\title{
Role of Multi-detector Computed Tomography in Medicolegal Evaluation of Non-Fatal Firearm Injuries in the Head in Assiut University Hospital
}

\author{
Khaled M. Abdel Aal' ${ }^{1}$ Hosam A. Yossef and Mohamed Zidan²
}

${ }^{1}$ Departments of Forensic Medicine and Clinical Toxicology
${ }^{2}$ Departments of Radio-diagnosis

Faculty of Medicine, Assiut University, Assiut, Egypt.

\begin{abstract}
Background: Firearm injuries may cause physical disabilities, permanent infirmities, psychological harm or death of injured individuals. Multi-detector computed tomography (MDCT) became a mainstay noninvasive diagnostic tool in investigation of firearm injuries as it gives three dimensional imaging (3-D) and colored images. Objective: This study was designed to through light on the role of MDCT in medicolagal evaluation of non-fatal firearm injuries in the head which examined in Assiut University hospital. Subjects and Methods: this study was conducted on 67 cases of non-fatal firearm injuries in the head including an age group 16-70 years which presented in the trauma unit and outpatient clinic of neurosurgery department during the period from June 2013 to June 2015. After forensic examination, the cases were examined blindly by two consultant radiologists using 16-row multi-detector CT in diagnostic radiology department of Assiut University hospital after giving an informed consent. The obtained images were post-processed using an advanced diagnostic computer workstation to obtain multi-planar reformatted and three-dimensional volume-rendered images to examine soft tissues, skull and intracranial structures. The relevant disclosing MDCT images were documented, interpreted and data were discussed between participants of the research from departments of the forensic medicine and diagnostic radiology and compared to results of forensic examination. Statistical analysis of data was done. Results: Most of injuries occurred in males which represented $89.45 \%$ of total cases and the highest percentage of victims was in the age group 21-30 years which represented $31.3 \%$. MDCT images help in determining details of inlets and exits (in soft tissue, bone and intracranial structures), recognizing the type of used firearm weapons (weapons firing shots represented $73.1 \%$ ), retained projectiles, determination of the distance of firing (79.1\% of total). In addition it demonstrated retained projectiles which represented $46.3 \%$ of total cases and their details (types, numbers, shapes, sizes, trajectory and deflection inside the skull), intracranial hemorrhage, edema, skull fractures. It can help in determination of permanent infirmity (which represented $17.9 \%$ of total cases) and in planning for surgical interference. Conclusion: This study demonstrated that MDCT is an accurate diagnostic tool in the medicolegal investigations of firearm injuries. The MDCT images are documented forensic evidence which can be stored, electronically sent for medicolegal consultation and can be shown in the court. In addition, medicolegal experts can trust on MDCT for determination of permanent infirmities which can help injured persons to obtain compensations and determine responsibility of physicians about faults in malpractice claims.
\end{abstract}

Keywords Computed tomography; medicolegal, firearm injuries, head, Assiut.

\section{Introduction}

Direarm-related injuries are a major problem worldwide, in forensic medicine practice (Cetin et al., 2013). They can result in deaths, disabilities, economic costs, greater utilization of health care system and burden on legal/police service in different communities (Weinberger et al., 2015). 
The craniocerebral trauma caused by firearms is a complex injury with high morbidity and mortality (Elserry et al., 2014).

Many factors implicated in increasing the incidence of firearm injuries such as trafficking, illegal supply of guns to criminals, robberies, assaults (Braga et al., 2012), during dispersing crowds (Scolan et al., 2012), falling bullets occur when guns are fired into the air during celebrations can cause serious injuries or even fatalities (Rapkiewicz et al., 2014).

Multidetector computed tomography (MDCT) becomes the gold standards in forensic investigations. It allows us to visualize all soft tissues, bones and internal organs (Brough et al., 2012). It is able to produce a vast quantity of high-resolution isotropic voxel data, gives maximum intensity projection, surface-shaded display or volume rendering technique and quality. Also it is a realistic multi-planar (sagittal, coronal and oblique) and gives (3-D) images. Reconstructions can be made; a feature that is specially useful when relating the patterns of injury to various circumstantial factors in the crime scene (Perandini et al., 2010).

Firearm wounds produced by higher velocity weapons may dissipate more energy into surrounding tissue and cause more tissue damage than low velocity weapons. The efficiency of energy transfer depends on the physical characteristics of the projectile, the kinetic energy, stability, entrance profile, path traveled through the body and the biological characteristics of the tissues injured. MDCT is the procedure of choice to identify anatomical structures, hemorrhage, air, bullets site and trajectory, bone fragments, nerve and musculoskeletal lesions (Reginelli et al., 2015)

In absence of soft-tissue finding of firearm injuries, MDCT can differentiate between inlet and exit wounds in the head from internal/external beveling of the skull bone. The chronologic order in which fractures were formed, since later fractures will typically stop at previously formed ones (Viel et al., 2009).

Gunshot residue (GSR) evidence may be altered or obscured by extensive burning or after-death events such as putrefaction, autolysis, and/or damage by animals. The microCT helps to differentiate between fresh and decomposed gunshot wounds and also between entrance and exit firearm wounds. GSR was concentrated on the skin surface around the entrance hole and in the epidermis and dermis around the cavity in fresh specimens while in decomposed specimens, the high density particles were detected only in the dermis. In addition the micro CT can estimate the firing distance. The GSR deposits of the firearm lesions inflicted at very close distance $(5 \mathrm{~cm})$ were formed of huge particles with an irregular shape and well-delineated edges but at greater distances (15 and $30 \mathrm{~cm}$ ) agglomerates of minute radiopaque particles scattered in the epidermis and dermis were obvious (Cecchetto et al., 2012 and Fais et al., 2013)
When cases of firearm injuries end by death, the MSCT of the head is a virtual autopsy can assist in identification of the victim's and assailant's age from teeth eruption, sinus examination, head dimensions and bone union. Also it helps in determination of sex, race and stature. It can yields further information on soft tissues whether extra or intracranial and vascular injuries (Grabherr et al., 2011 and Manigandan et al., 2015).

In certain cultural circles where conventional autopsy is stigmatized or even forbidden, virtual autopsy by MDCT would allow sound medicolegal practice without violating religious prohibitions or personal reservations (Weber, 2001).

Although there were a lot of articles about the role of MDCT in evaluation of firearm injuries have been published abroad, its value in evaluation of firearm injuries in Upper Egypt population has not been investigated or published before for the extent of my knowledge.

\section{Aim of the Work}

This study aimed at demonstrating the importance of implementing MDCT with different post-processing multi-planar reformatted and volume rendered 3Dmodeling techniques in the medicolegal evaluation of non fatal firearm injuries in the head of cases examined in Assiut University Hospital.

\section{Subjects and Methods}

\section{Subjects}

Sixty seven Upper Egypt individuals (60 males and 7 females) were included in this study in Assiut University Hospital after giving an informed consent. The individuals included in this prospective study were non fatal firearm injured persons, aged 16-70 years, presenting at the diagnostic radiology department for head CT investigation after admission in the trauma unit and outpatient clinic of neurosurgery department of Assiut University Hospital during the period from June 2013 to June 2015. Exclusion criteria include persons admitted for non firearm injuries, firearm injuries not present in the head or fatal firearm injuries. Prior to blinded MDCT examination, the history was taken and forensic examination was done. Then comparison between findings of MDCT images and some clinical examination between members of diagnostic radiology and forensic medicine departments were obtained for every injured person.

\section{Methods}

MDCT examinations were performed using a16-row multi-detector CT (Light Speed 16; GE Medical Systems, Milwaukee, Wisconsin). The scanning protocol consisted of $1.25 \mathrm{~mm}$ collimation, reconstruction interval of $0.625 \mathrm{~mm}$, tube voltage of $120 \mathrm{kV}$, tube current of 180-230 mA, and 16 slices per half second. The obtained images were then retrospectively reconstructed at the $\mathrm{CT}$ machine 
console to a section thickness of $0.625 \mathrm{~mm}$ prior to be sent to the post-processing workstation (Synapse 3D, Fujifilm Medical, Tokyo, Japan).

\section{Ethical Consideration}

This work was done after approval from the Research and Ethical Committee of Faculty of Medicine, Assiut University. Informed consent was taken from all individuals participated in this study. Confidentiality of information obtained from all persons included or excluded in this study during MDCT examination was maintained by keeping the medical reports anonymous.

\section{Statistical Analysis}

The data collected were organized, tabulated, entered into a computer database program using SPSS (Statistical Package for the Social Sciences) software version 20. Chi-square test was used to find the significant differences between the percentages of studied parameters. When $\mathrm{p}$. value $\leq 0.01$ is highly significant, $\leq 0.05$ is significant and $>0.05$ is not significant (Kirwood et al., 2003).

\section{Examples of some studied cases}

\section{Case (1)}

A 24 years old man presented in trauma unit with nonfatal shotguns injury intentionally inflicted by another in the head. Examination revealed that the explosive blast effect of the weapon caused lacerations of the skin and muscles of the upper and lower lids of the left eye, with loss of the skin of an adjacent large area of the left temple. Most of the gunshots were lodged within the skin and subcutaneous tissues of the face and scalp, but multiple gunshots were retained inside both orbits causing bilateral rupture of the eye globes. Other gunshots could penetrate inside the skull through the left orbit causing subarachnoid hemorrhage and pneumocephalus

\section{MDCT images: figures (1-5)}

\section{Case (2)}

A 36 years old man presented in trauma unit with nonfatal homicidal shotgun injury in the head with loss of vision. Most of the gunshots were of small size and were embedded in the skin and subcutaneous tissues of the face and scalp, especially on the left side, including the upper and lower lids of the left eye. There was no direct skull bone penetration, but the gunshots could penetrate inside the skull by passing through the superior orbital fissure of the left orbit. The penetrating gunshot caused fracture of the lateral rim of the superior orbital fissure leaving small bone fragments. The path of the penetrating gunshot could be traced

\section{Results}

Table (1): shows Chi-square statistical analysis of age distribution of the studied sample. The mean of all studied age groups ranges between $34.9+6.7$ years. The percentage of age groups $>20-30$ years and $>30-40$ years showed highly significant statistical increase as compared to all other age groups.

Table (2): shows Chi-square statistical analysis of gender distribution of non fatal firearm injuries of the studied Upper Egyptian sample by MSCT. The higher percentage of injuries was found in males which represented $89.55 \%$ while females represented $10.45 \%$ of total cases.

Table (3): shows Chi-square statistical analysis of findings of MDCT and some clinical \& forensic examination of studied non fatal firearm injuries in the head. There were non-statistical significant difference between the two methods in determination of weapon type, sites of inlets and exits, distance of firing. MDCT showed high percentage in detection of permanent infirmity than the clinical examination alone.

through the left orbit and into the brain where it created a permanent defect marked by pellets to be finally retained in the left occipital lobe. There was no clinical or CT evidence of rupture of the left eye-globe but MDCT revealed the gunshots caused cutting of the optic nerve close to the orbital apex. Reformatted MDCT images could accurately detect the gunshot path and trajectory as well as its orbital injuries and the intracranial injuries including subarachnoid hemorrhage seen posterior to the left orbit.

MDCT images: figures (6 -12).

\section{Case (3)}

A 17 years old young man with non-fatal accidental firearm injury (stray bullets) presented in neurosurgery outpatient clinic two months after shooting. There was a left frontal bone inlet wound with the main bulk of the bullet lodged in the skull bone defect. A large shrapnel of the trapped bullet could penetrate into the skull, with multiple pellets and bone fragments seen at the inner aspect of the inlet and along the permanent parenchymal defect created along the path of the shrapnel through the upper part of the left cerebral hemisphere. The bullet couldn't exit the skull, instead it changed its direction and swerved downwards forming a side-branch of the permanent defect at the end of which the bullet was finally retained. Reformatted MDCT images could clearly demonstrate the path of the bullet and depict its trajectory.

MDCT images: figures (13 -17). 
Table (1):Chi-square statistical analysis of age distribution of the studied sample.

\begin{tabular}{|c|c|c|c|c|}
\hline Age Groups & No. & $\%$ & Chi-square $\left(\mathrm{x}^{2}\right)$ & P. value \\
\hline$\leq 20 \mathrm{Y}$ & 8 & $11.9^{\mathrm{ab}}$ & \multirow[t]{7}{*}{27.5} & \multirow[t]{7}{*}{$<0.001 * *$} \\
\hline$>20-30 \mathrm{Y}$ & 21 & 31.3 & & \\
\hline$>30-40 \mathrm{Y}$ & 19 & 28.4 & & \\
\hline$>40-50 \mathrm{Y}$ & 10 & $14.9^{\mathrm{a}}$ & & \\
\hline$>50-60 \mathrm{Y}$ & 6 & $9^{\mathrm{ab}}$ & & \\
\hline$>60-70 \mathrm{Y}$ & 3 & $4.5^{\mathrm{ab}}$ & & \\
\hline Total & 67 & 100.0 & & \\
\hline Mean \pm SD & & & & \\
\hline
\end{tabular}

a Statistically significant as compared with age group >20-30 Y, b Statistically significant as compared with age group $>30-40 Y$.

Table (2): Chi-square statistical analysis of gender distribution of studied cases of non-fatal firearm injuries in the head

\begin{tabular}{|l|c|c|}
\hline \multicolumn{1}{|c|}{ Gender } & No. & Percent \\
\hline Females & 7 & $10.45 \%$ \\
\hline Males & 60 & $89.55 \%$ \\
\hline Total & 67 & $100 \%$ \\
\hline Chi-square & \multicolumn{2}{|c|}{$0.000 * *$} \\
\hline P value & \multicolumn{2}{|c|}{0.8} \\
\hline P. value $* * \leq 0.01$ highly significant, ${ }^{*} \leq 0.05$ significant, $>0.05$ not significant $(\mathrm{Ns})$.
\end{tabular}

Table (3): Chi-square statistical analysis of findings of MDCT and some clinical \& forensic examination of studied non fatal firearm injuries in the head.

\begin{tabular}{|c|c|c|c|c|c|c|c|}
\hline \multicolumn{2}{|c|}{ Parameters } & \multicolumn{2}{|c|}{$\begin{array}{c}\text { MDCT } \\
\text { examination }\end{array}$} & \multicolumn{2}{|c|}{$\begin{array}{c}\text { Some clinical \& } \\
\text { forensic ex. }\end{array}$} & \multirow{3}{*}{$\begin{array}{c}\begin{array}{c}\text { Chi- } \\
\text { square }\end{array} \\
0.0\end{array}$} & \multirow{3}{*}{$\begin{array}{c}\begin{array}{c}P . \\
\text { value }\end{array} \\
1.0^{\mathrm{ns}}\end{array}$} \\
\hline & & \multirow{2}{*}{$\begin{array}{c}\text { No. } \\
67\end{array}$} & \multirow{2}{*}{$\begin{array}{c}\% \\
100\end{array}$} & \multirow{2}{*}{$\begin{array}{c}\text { No. } \\
67\end{array}$} & \multirow{2}{*}{$\begin{array}{c}\% \\
100\end{array}$} & & \\
\hline Inlet and exit & Inlets & & & & & & \\
\hline Wounds & Exits & 36 & 53.7 & 36 & 53.7 & 0.0 & $1.0^{\mathrm{ns}}$ \\
\hline $\begin{array}{l}\text { Sites of } \\
\text { injuries }\end{array}$ & $\begin{array}{l}\text {-Soft tissue (extra-cranial) } \\
\text { - Skull and mandible } \\
\text { - Intracranial }\end{array}$ & $\begin{array}{l}67 \\
24 \\
31 \\
\end{array}$ & $\begin{array}{l}100 \\
35.8 \\
46.3 \\
\end{array}$ & $\begin{array}{c}67 \\
9 \\
0.0 \\
\end{array}$ & $\begin{array}{c}100 \\
13.4 \\
0.0 \\
\end{array}$ & 9.8 & $0.002 * *$ \\
\hline \multirow[t]{2}{*}{$\begin{array}{l}\text { Shape of } \\
\text { Wounds }\end{array}$} & $\begin{array}{l}\text {-Typical inlets } \\
\text { - A typical inlet }\end{array}$ & $\begin{array}{c}58 \\
9\end{array}$ & $\begin{array}{l}86.6 \\
13.4\end{array}$ & $\begin{array}{c}58 \\
9\end{array}$ & $\begin{array}{l}86.6 \\
13.4\end{array}$ & 0.0 & $1.0^{\mathrm{ns}}$ \\
\hline & $\begin{array}{l}\text { - Typical exit } \\
\text { - A typical exit }\end{array}$ & $\begin{array}{c}30 \\
6 \\
\end{array}$ & $\begin{array}{l}83.3 \\
16.7 \\
\end{array}$ & $\begin{array}{c}30 \\
6 \\
\end{array}$ & $\begin{array}{l}83.3 \\
16.7 \\
\end{array}$ & 0.0 & $1.0^{\mathrm{ns}}$ \\
\hline Multiplicity of wounds & $\begin{array}{l}\text {-Single } \\
\text {-Multiple }\end{array}$ & $\begin{array}{l}17 \\
50 \\
\end{array}$ & $\begin{array}{l}25.37 \\
74.63\end{array}$ & $\begin{array}{l}17 \\
50 \\
\end{array}$ & $\begin{array}{l}25.37 \\
74.73 \\
\end{array}$ & 0.0 & $1.0^{\mathrm{ns}}$ \\
\hline \multirow[t]{2}{*}{ Type of weapon } & - Weapons firing shots & 49 & 73.1 & 49 & 73.1 & 0.0 & $1.0^{\mathrm{ns}}$ \\
\hline & - Weapons firing bullets & 18 & 26.9 & 18 & 26.9 & 0.0 & $1.0^{\mathrm{ns}}$ \\
\hline $\begin{array}{l}\text { Direction of } \\
\text { Firing }\end{array}$ & $\begin{array}{l}\text { Perpendicular } \\
\text { - Oblique }\end{array}$ & $\begin{array}{l}51 \\
61 \\
\end{array}$ & $\begin{array}{l}76.1 \\
23.9 \\
\end{array}$ & $\begin{array}{l}51 \\
61 \\
\end{array}$ & $\begin{array}{l}76.1 \\
23.9 \\
\end{array}$ & 0.0 & $1.0^{\mathrm{ns}}$ \\
\hline Distance & $\begin{array}{l}\text { - Near distance } \\
\text { - Distant distance }\end{array}$ & $\begin{array}{l}14 \\
53 \\
\end{array}$ & $\begin{array}{l}20.9 \\
79.1 \\
\end{array}$ & $\begin{array}{l}14 \\
53 \\
\end{array}$ & $\begin{array}{l}20.9 \\
79.1 \\
\end{array}$ & 0.0 & $1.0^{\mathrm{ns}}$ \\
\hline \multicolumn{2}{|c|}{$\begin{array}{l}\text { Permanent infirmity (rupture globe, cranial nerves or } \\
\text { neurological damage, epilepsy \& skull defects) }\end{array}$} & 12 & 17.9 & 7 & 10.4 & 0.99 & $0.407^{\mathrm{ns}}$ \\
\hline
\end{tabular}

$P$. value $* * \leq 0.01$ highly significant, $* \leq 0.05$ significant, $>0.05$ not significant $(\mathrm{Ns})$. 

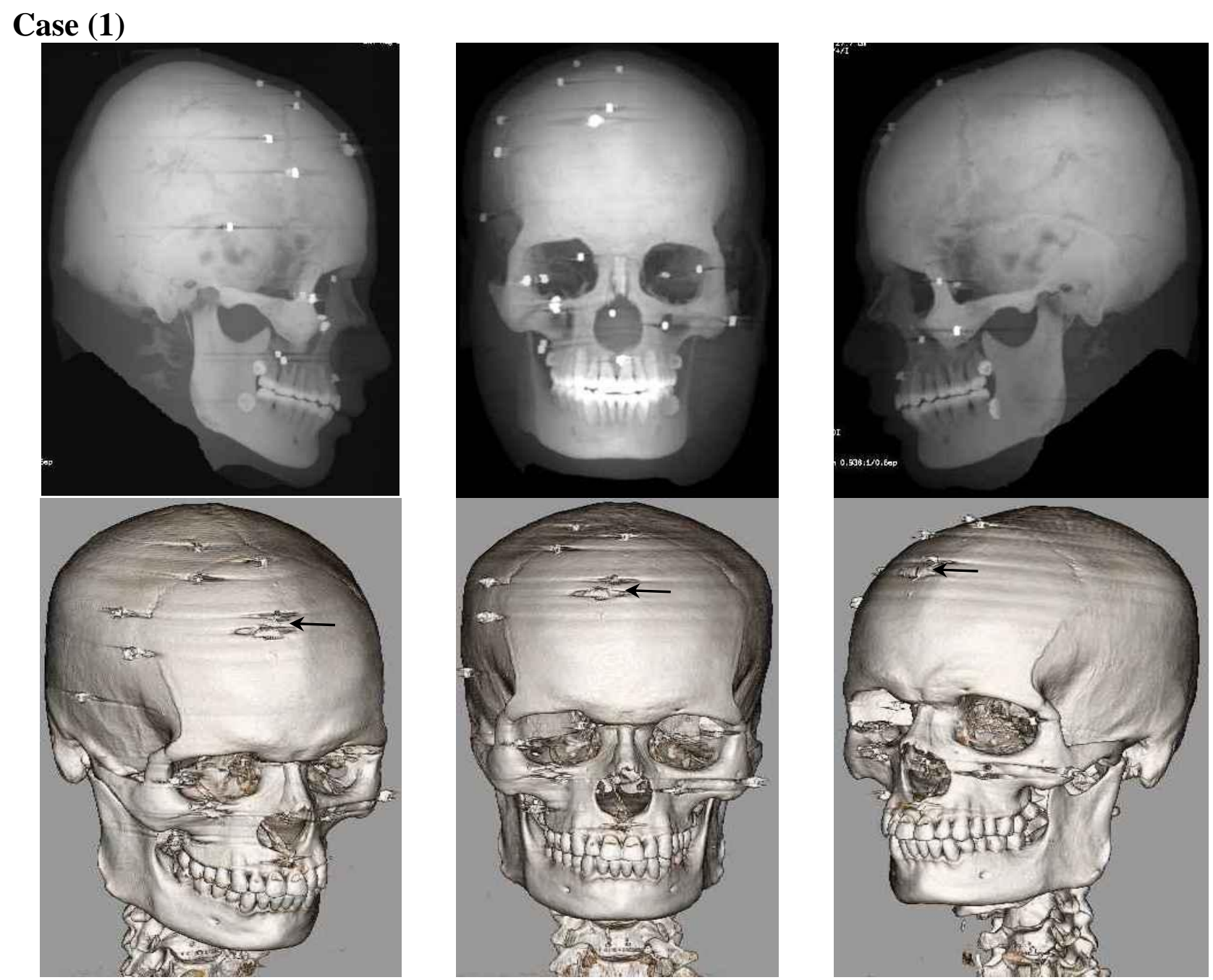

Fig (1): Two types of 3D volume rendered models of the head; the images in the upper row display faint shadow of the soft tissues overlying the skull, appearing transparent, and showing retained gunshots. The images of upper raw show much less metallic artifacts (arrow) than images of bare bone in the lower row, they are due to beam hardening effect.
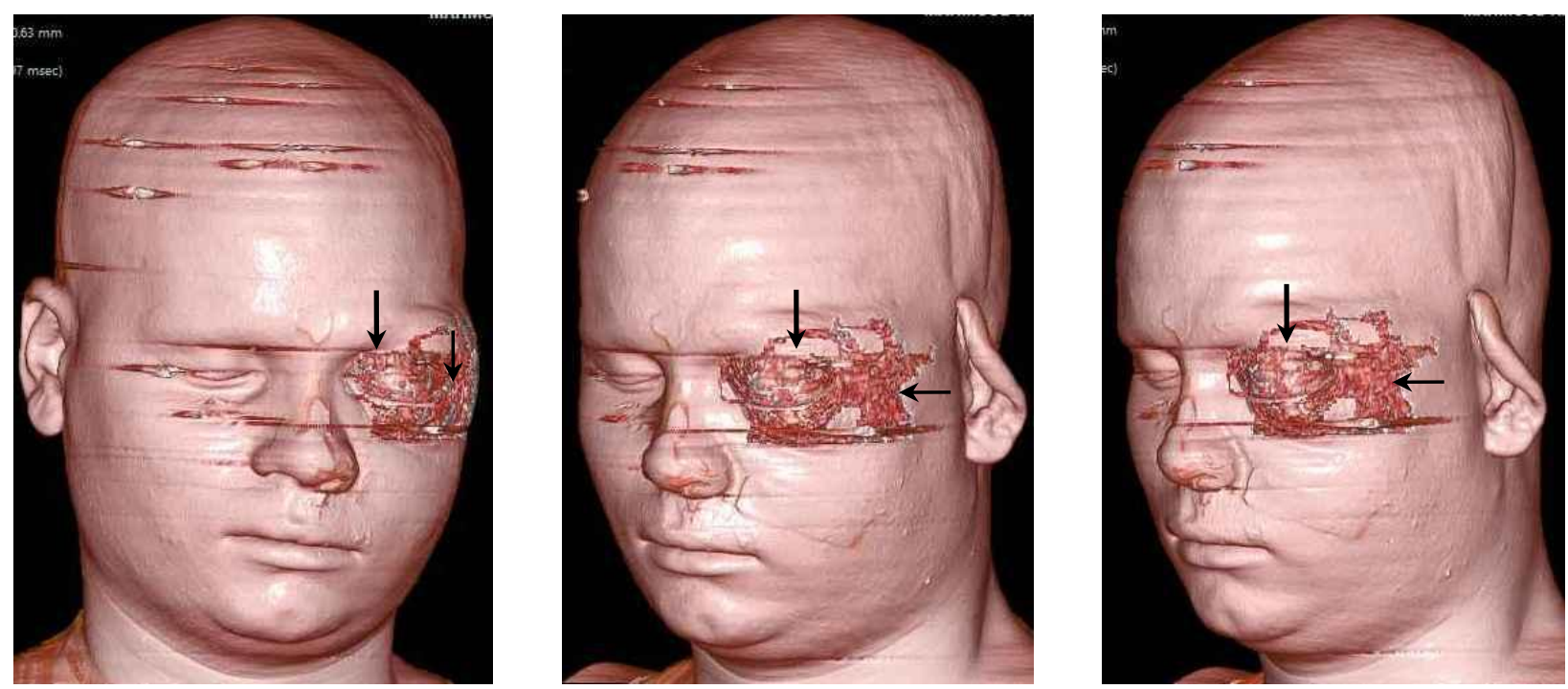

Fig (2): Shaded-surface display volume rendered model of the head; the lacerations of the upper and lower lids of the left eye and the underlying muscles (broad arrow) as well as the laceration of the adjacent skin (narrow arrow) are clearly seen. 

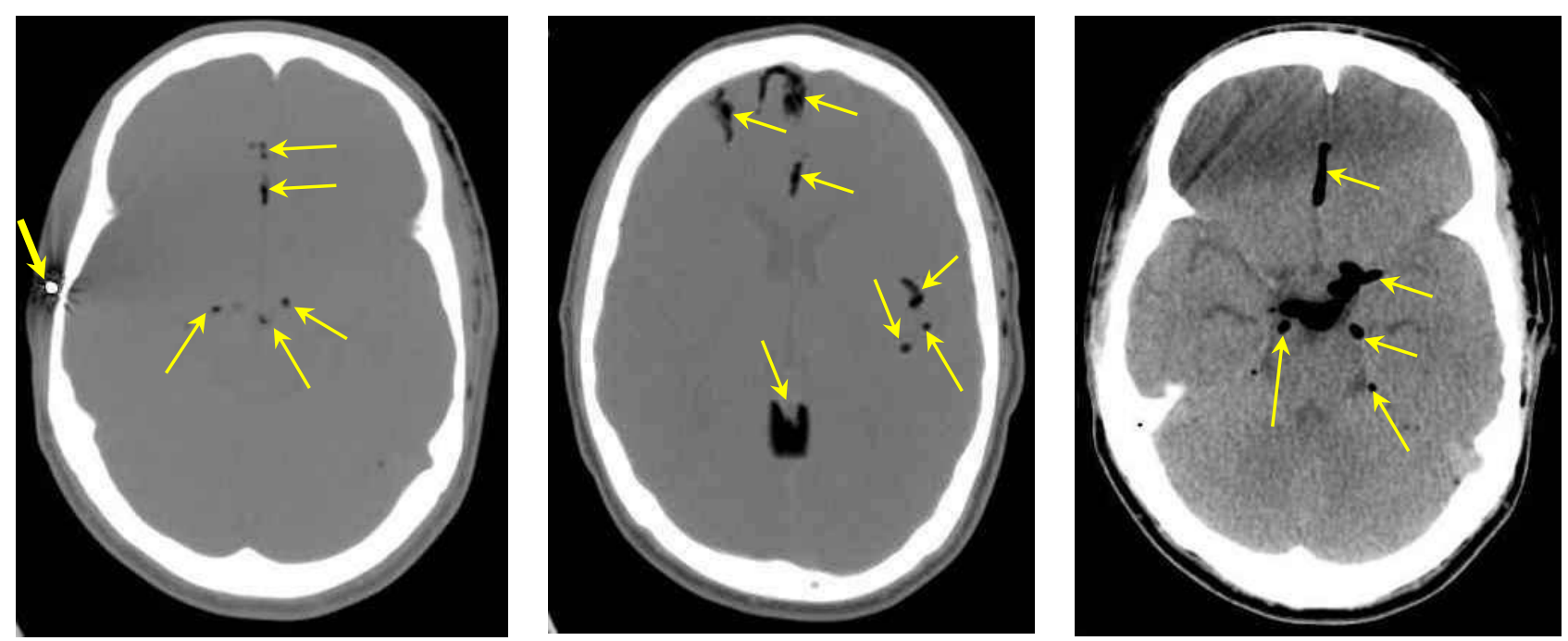

Fig (3): Axial images of the head at different window width and level settings, showing gas-density (pneumocephalus) within the subarachnoid space, basal cisterns, inter-hemispheric fissure and supracellar (thin arrows) suggesting penetration of the ethmoidal air cells by the gunshots. A small gunshot is seen within the layers of the scalp overlying the right temple in the first image (thick arrow).
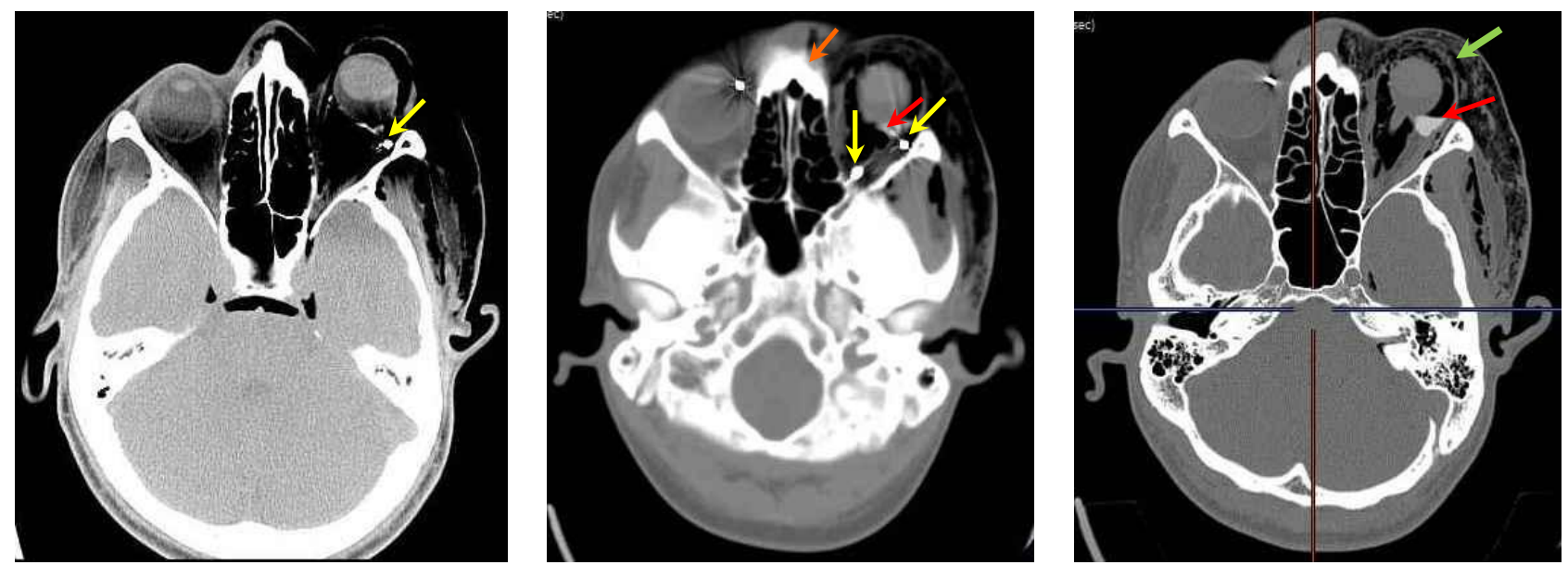

Fig (4): Axial images of the head; showing retained gunshots within the left orbit (yellow arrow) with rupture of the left eye-globe seen smaller in size with blood density inside and around (red arrow), and marked edema (green arrow) which causes swelling of the eyelids and adjacent skin of the left temple.
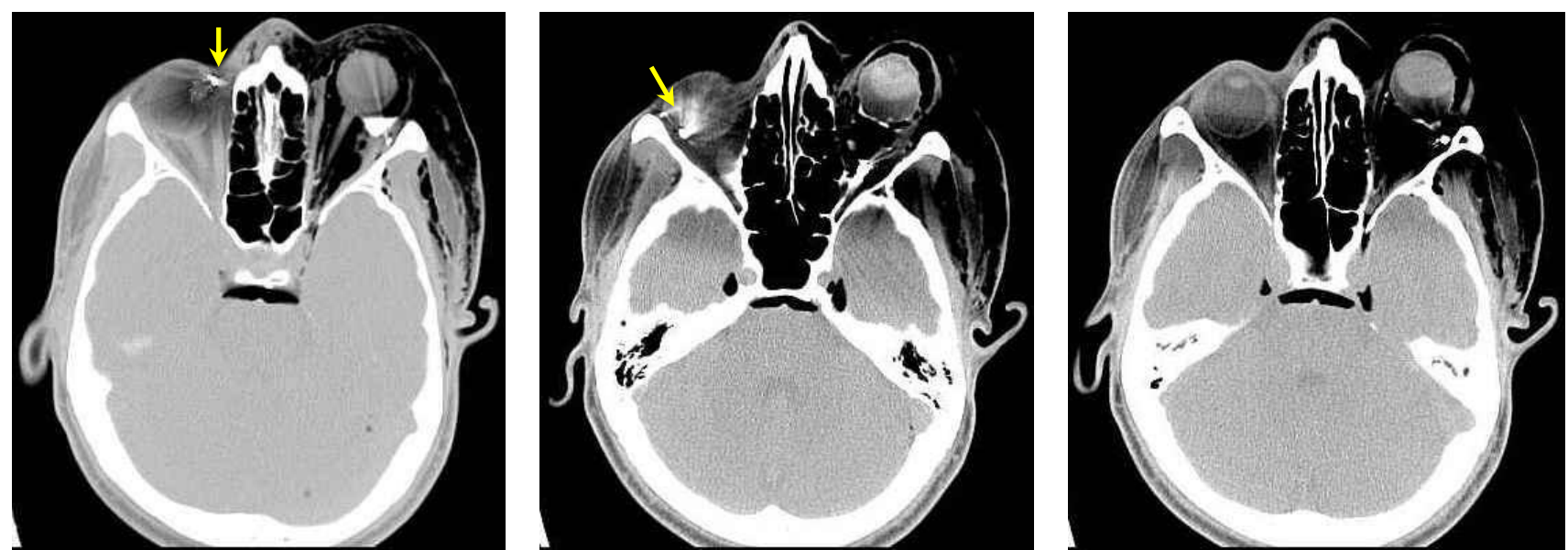

Fig (5): Axial images of the head; showing retained gunshots within the medial and lateral sides of the right orbit (yellow arrow), however the eyeball seems intact. 
Case (2):

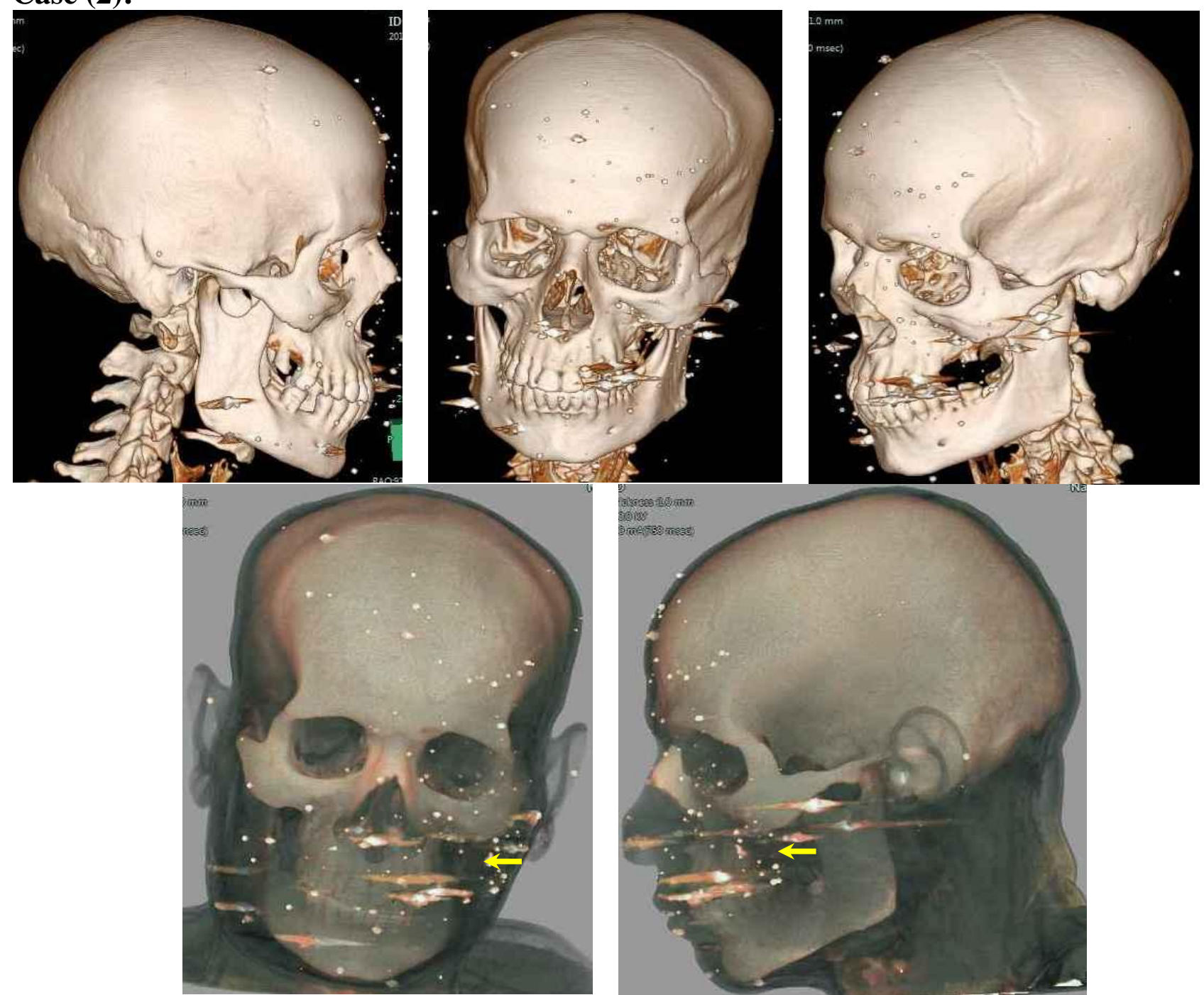

Fig (6): Volume-rendered 3D-models of the head; the images in the upper row show the bare-bone of the skull, while the images in the lower row show transparent shadow of the soft tissues of the face, scalp and neck. There's large number of small gunshots embedded within the soft tissues, mainly on the left side (arrow).
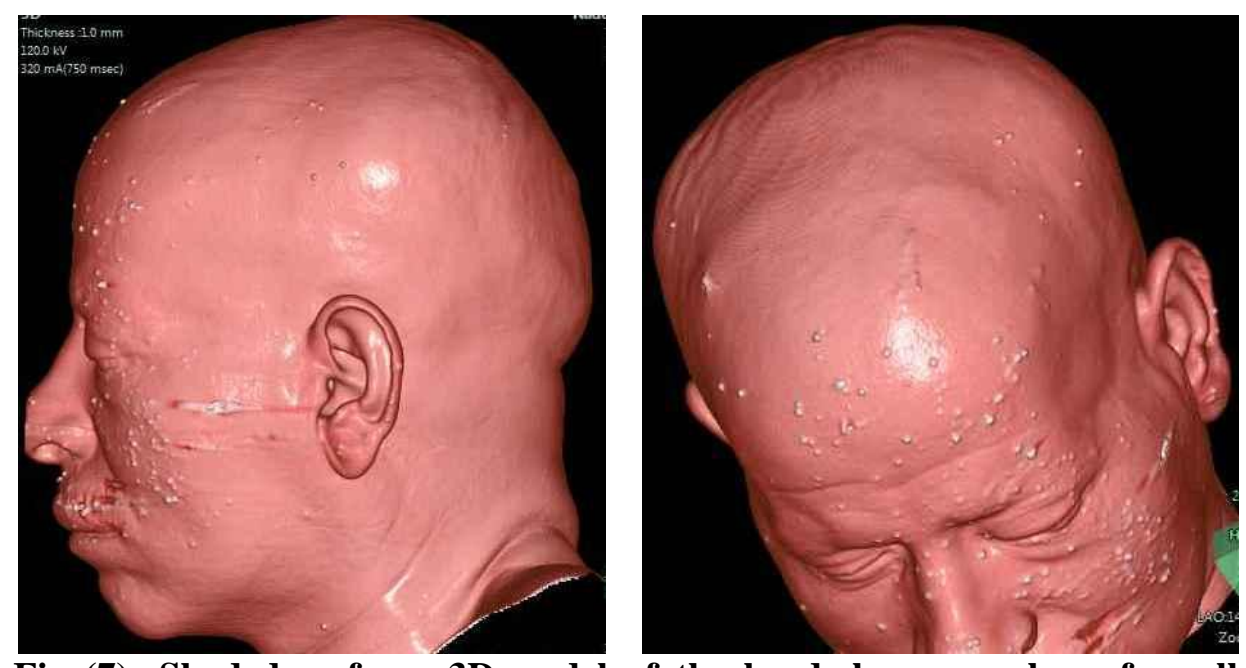

Fig (7): Shaded-surface 3D-model of the head; large number of small gunshots embedded within the skin of the face and the scalp. 

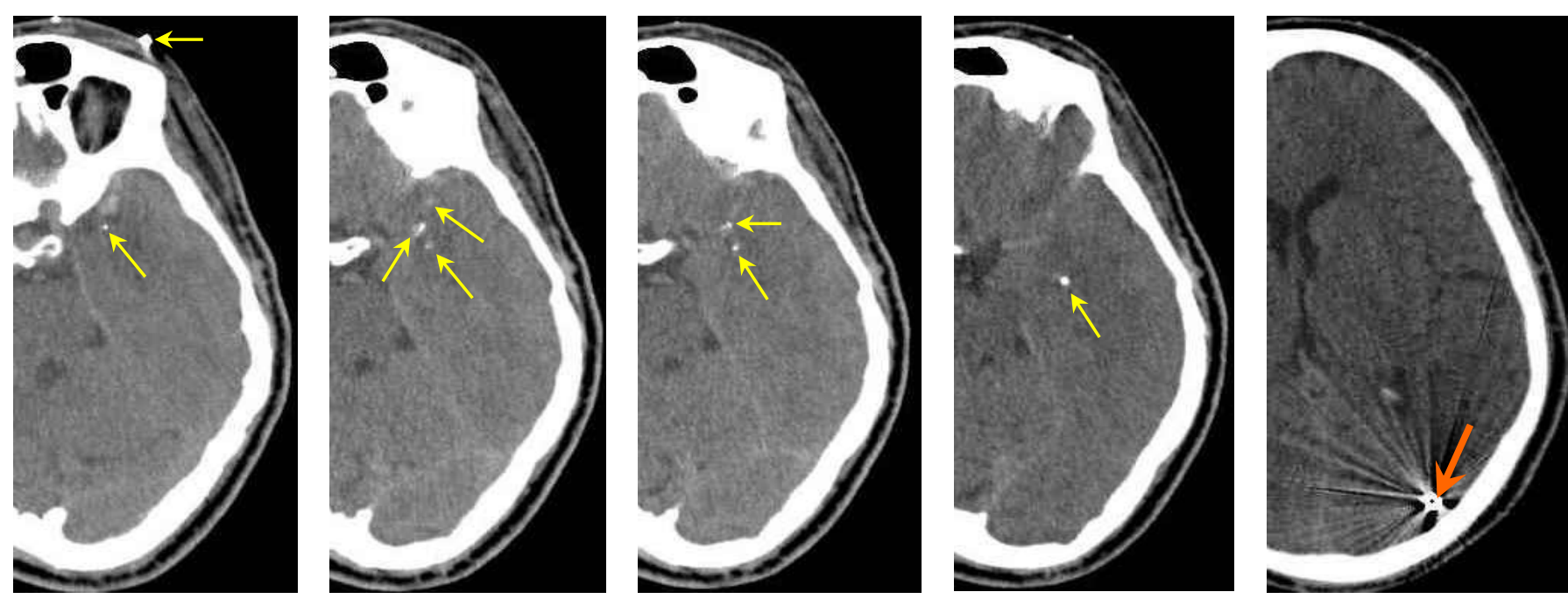

Fig (8): Axial reformatted images of the head showing multiple small metallic fragments along the path of the retained gunshots (yellow arrows) along a line extending from the apex of the left orbit till its final position in the left occipital lobe (orange arrow) at different anatomical levels.
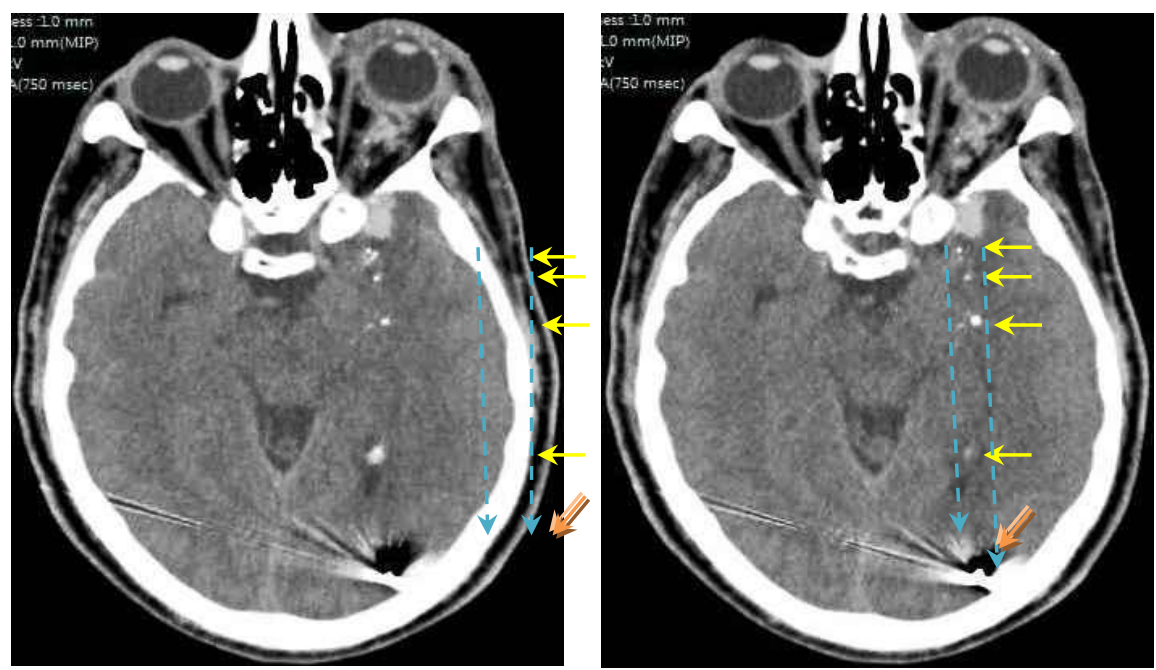

Fig (9): Axial reformatted images of the head showing the whole path of the retained left occipital gunshot (orange arrow) delineated by the small metallic fragments (yellow arrows). The two interrupted lines outline the full length of the bullet path
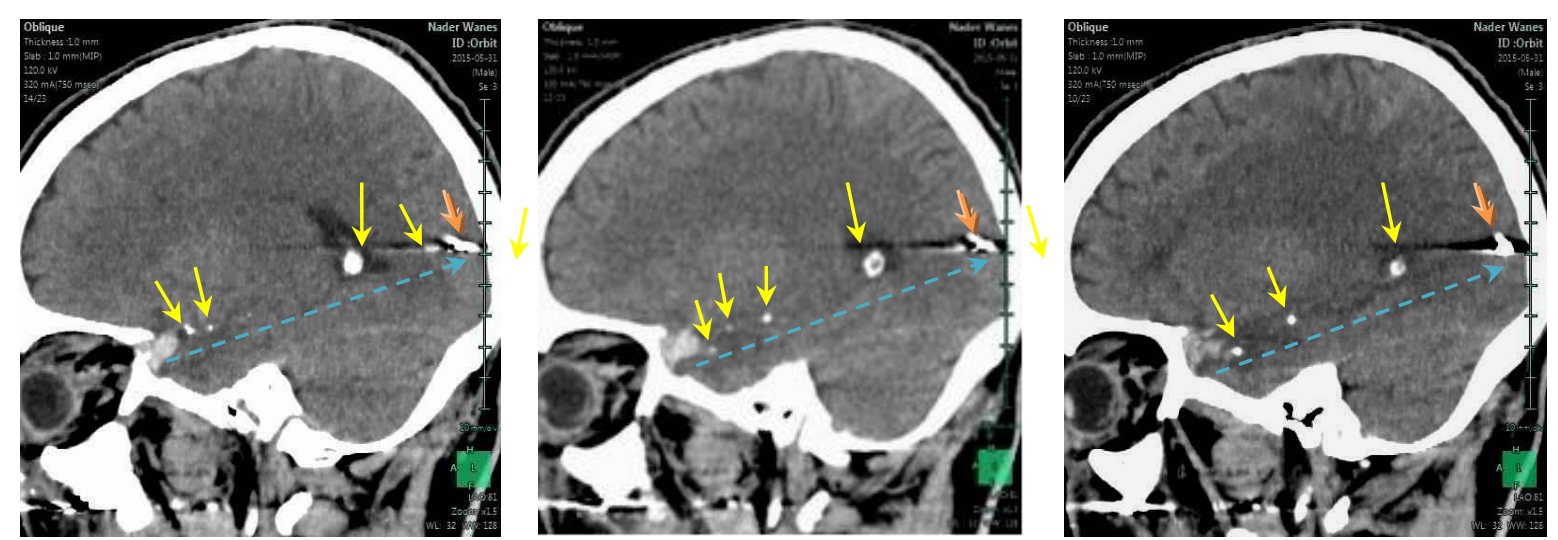

Fig (10): Sagittal reformatted images of the head showing the path of the retained left occipital gunshot (orange arrow) delineated by the small metallic fragments along the path course (yellow arrows). The interrupted lines represent the bullet path 

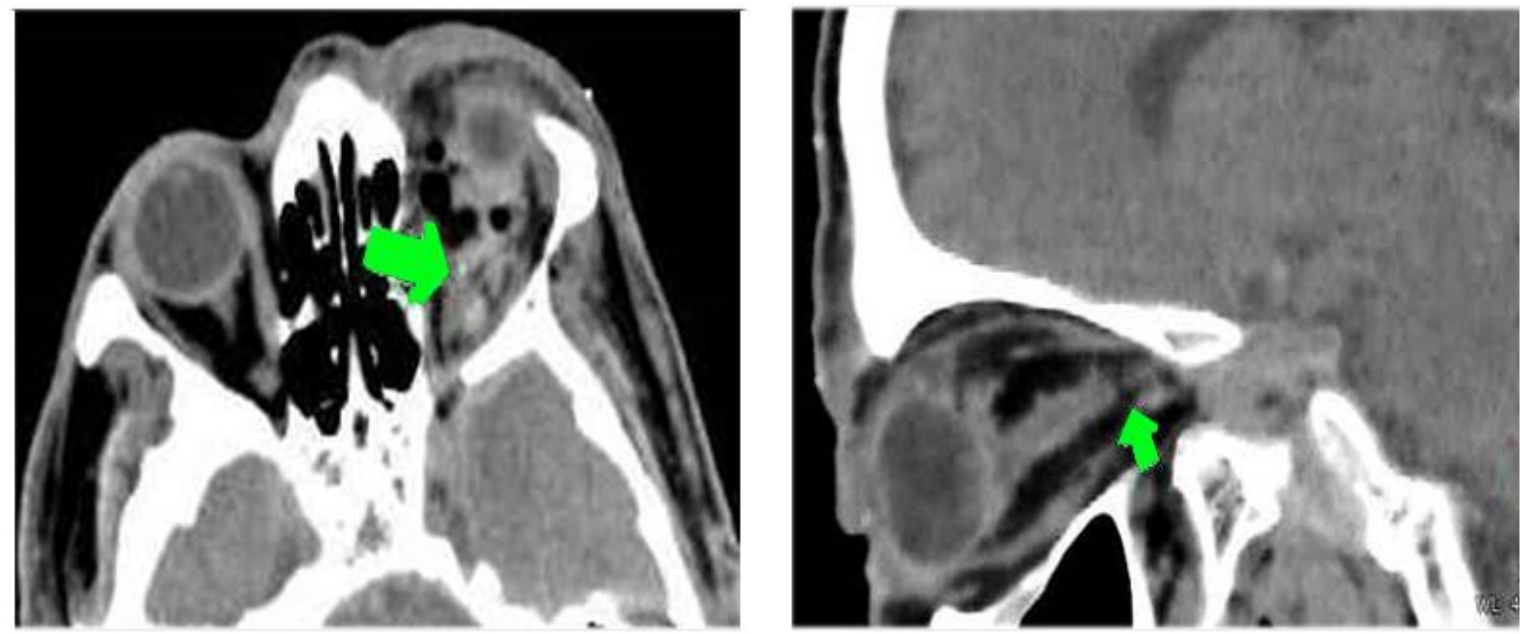

Fig (11): Axial \& sagittal reformatted images of the head through the orbits, showing irregularity and haziness of the contents of the left orbit in axial images, and evident disruption of the continuity of the left optic nerve in sagittal reformatted images (green arrow in sagittal image).
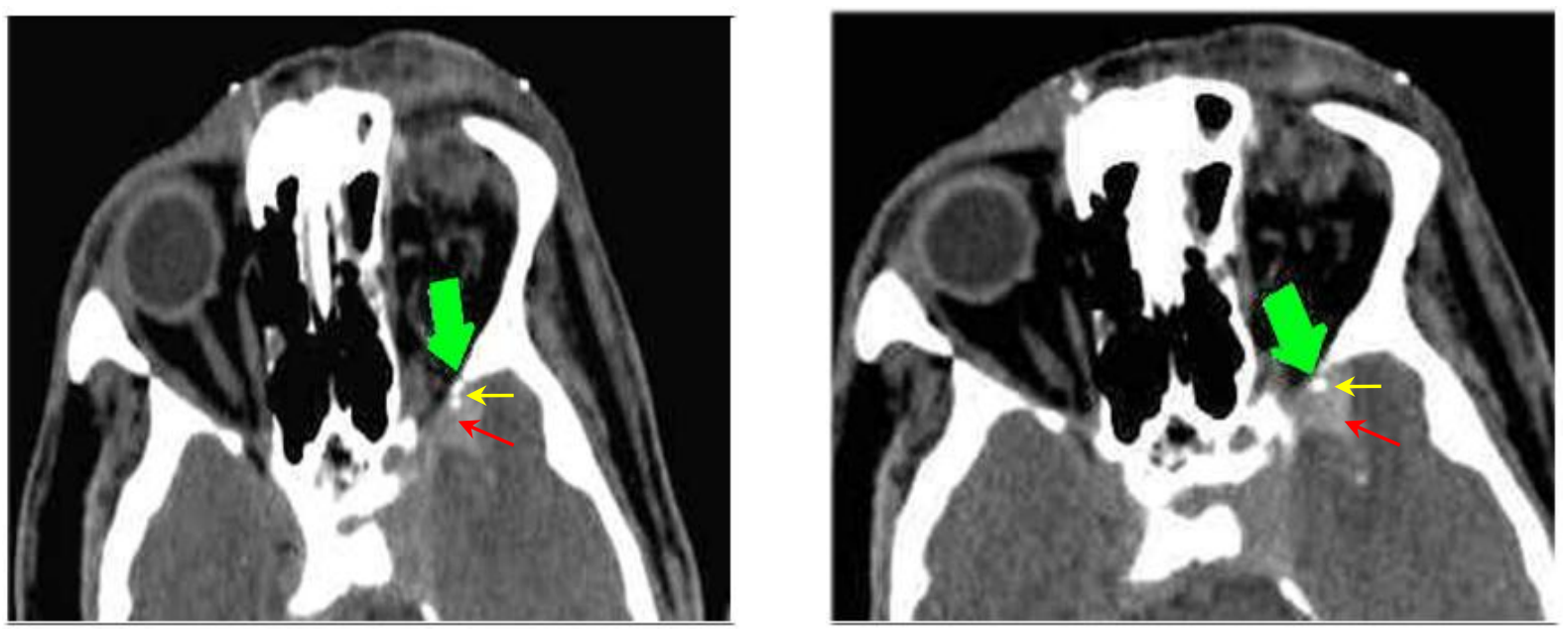

Fig (12): Axial images through both orbits, showing fractured lateral wall of the superior orbital fissure with small bone fragments (green arrows), this represents the inlet through which the retained left occipital gunshots (yellow arrows) had penetrated into the cranium, associated with subarachnoid hemorrhage (red arrow).

\section{Case (3)}
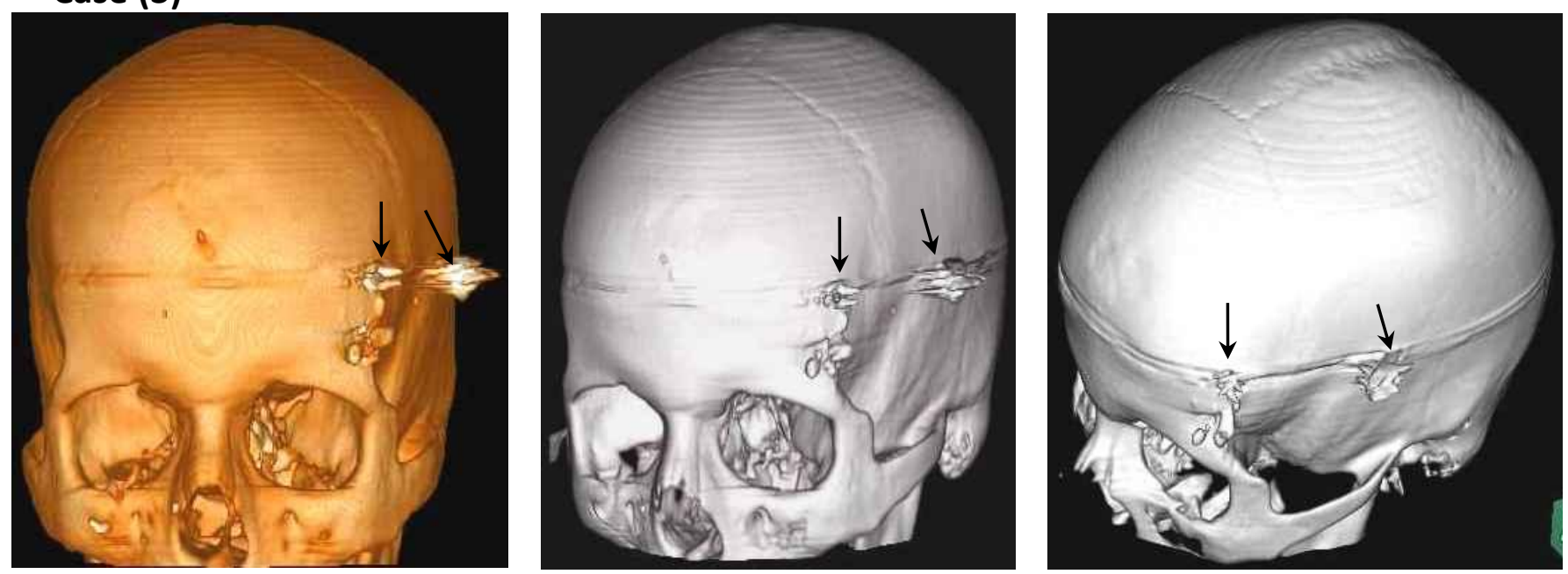

Fig (13): Volume-rendered 3D-models of the head; showing the bullet impacted in the left frontal bone surrounded by small bone and metallic fragments. The retained subgalial shrapnel in the left temporal region is also seen. The bullet causes marked beam-hardening artifacts (black arrows). 

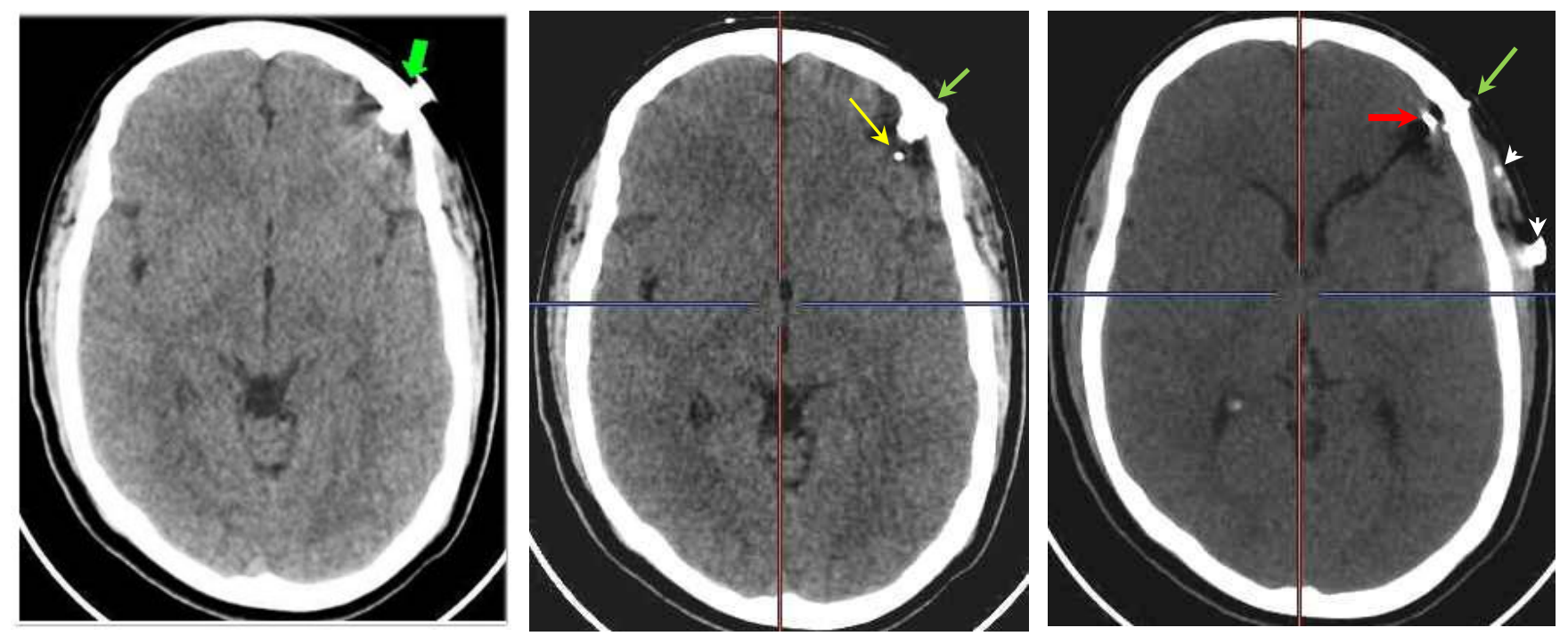

Fig (14): Axial reformatted images of the head, brain window settings, showing the impacted bullet at the inlet defect through the left frontal bone (thick green arrow). A small metallic fragment (yellow arrow) and bone fragment (red arrow) are seen inside the skull. The focal lacero-contusive parenchymal defect in the left frontal lobe of the brain is well-seen. The retained bullet deep to the scalp in the left temporal region is also seen (white arrowheads).
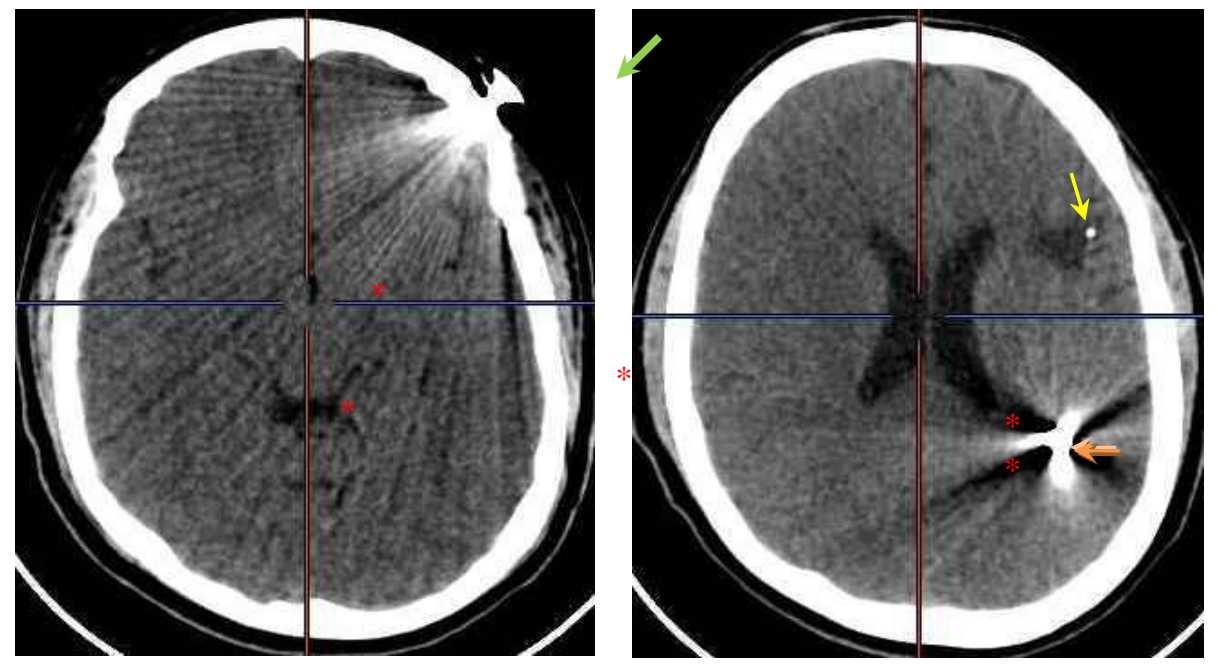

Fig (15): Axial reformatted images of the head showing the impacted bullet at its inlet in the left frontal bone (green arrow) and the location of the retained (impacted) bullet in the left parietal region (yellow arrow). The streak artifacts of the bullet are well seen $(*)$. 

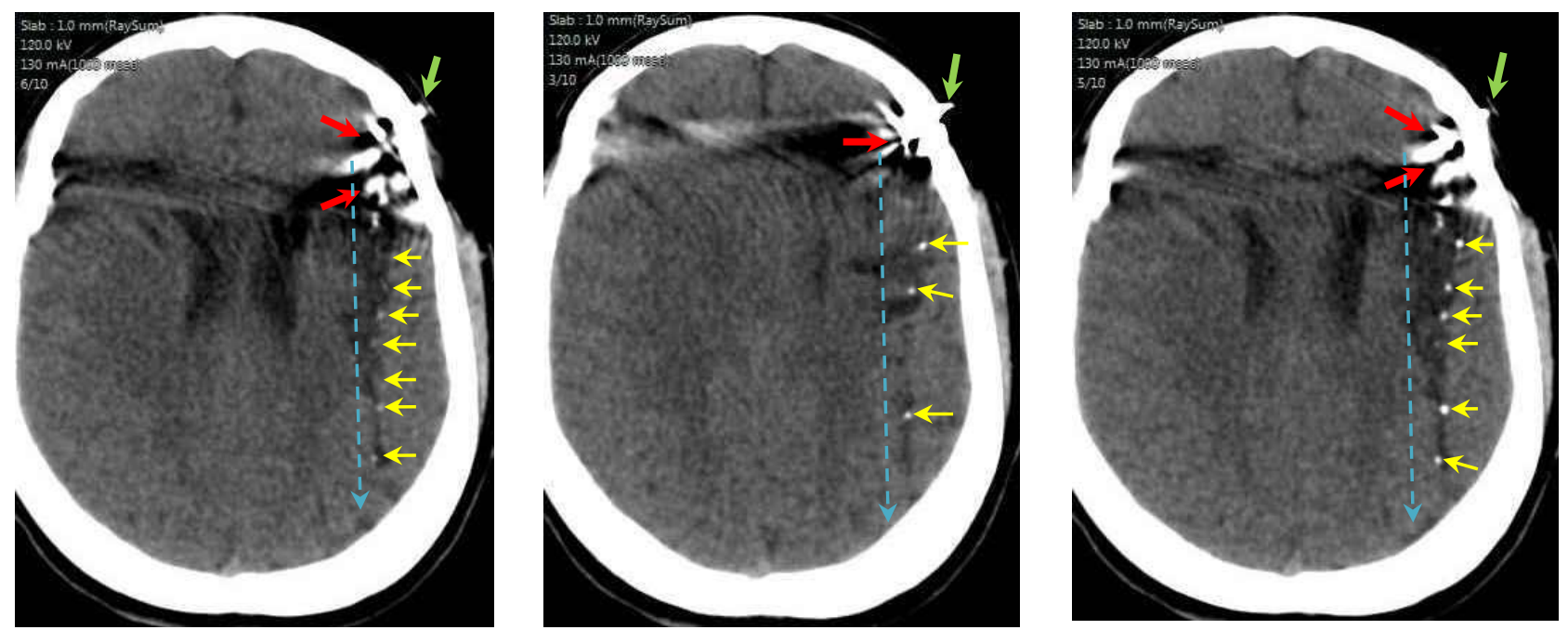

Fig (16): Axial reformatted images of the head showing the permanent defect of the path (orange arrow) of the retained fragmented bullet marked by small metallic fragments (yellow arrows). However, the retained bullet is not seen at the end of its track.

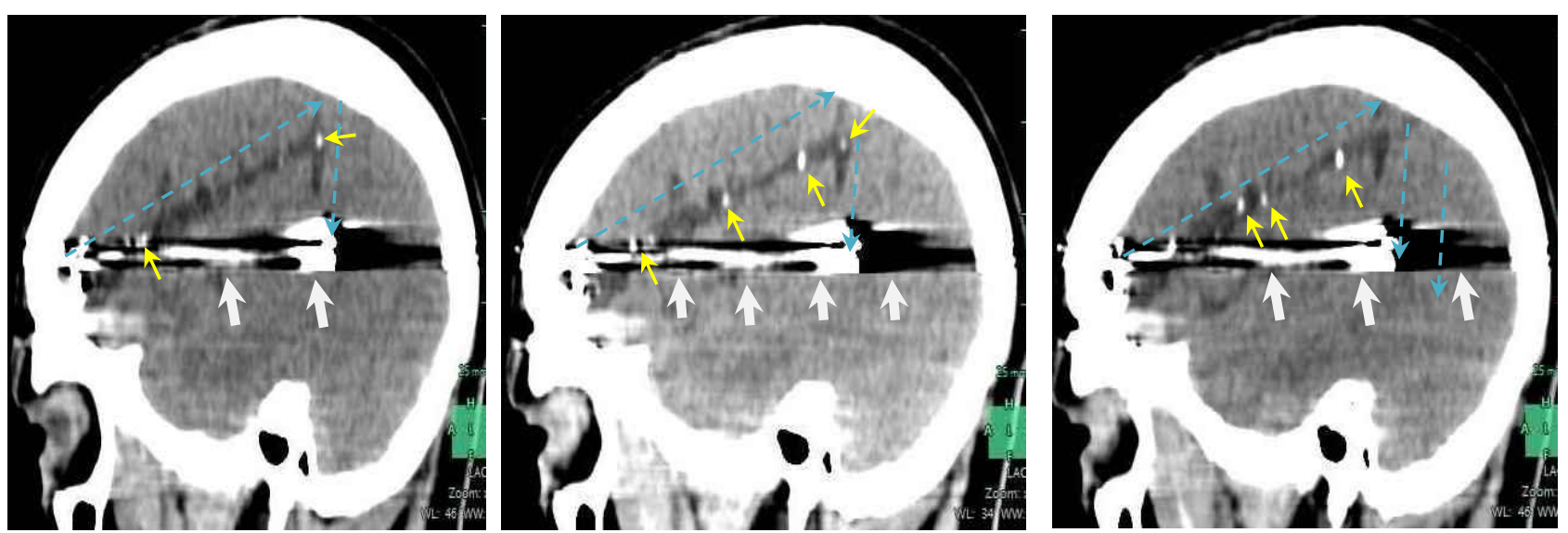

Fig (17): Sagittal reformatted images of the head showing the permanent defect of the path of the retained bullet delineated by multiple small metallic fragments (yellow arrows). The bullet changed its direction being unable to exit the skull, and was deflected downward through a side-branch at the end of its original path to its final position. Severe beam hardening artifacts are seen (yellow arrows).

However, the retained bullet is not seen at the end of its track

\section{Discussion}

Firearm Injuries is a community problem worldwide which severely affects the criminal justice and healthcare systems. It may cause significant morbidity, longterm physical and psychological disability for individuals, families, communities and societies. In addition to the hospitalizations costs, the injuries may end in death (Sachan et al., 2013, Shultz et al., 2014 and Agarwal, 2015).

Firearm injuries may result in facial or intracranial injuries and skull fractures. It may result from un-intentional injuries, suicides and homicide (Allareddy et al., 2014).

The forensic pathologists have been increasingly utilizing 3D-MDCT in firearm wounds investigations. It can help in the documentation of the extent of cranio-cephalic injury, in crime scene reconstruction and corroborating circumstantial evidence (Colard et al., 2013).

MDCT is widely used to detect and document forensic evidence for medicolegal situations in an

unbiased and comprehensible fashion, being minimally-invasive and observer-independent diagnostic tool both in the living and the deceased. It provides an excellent tool for crime reconstruction, including 3D true color scaled representations of injuries and even 3D models of events (Puentes et al., 2009).

Tartaglione et al. (2012) stated that CT is an excellent tool for addressing the most important questions of forensic medicine in the case of gunshot wounds of the head.

Ebert et al., (2015) mentioned that computerassisted diagnostic systems are continuously developed that permit imaging data sets to be quickly and intuitively re-sliced and reconstructed in real time to narrow the gap between radiologic imaging and autopsy. It can replace autopsy if firearm injuries end in death later on from the complications. Using crosssectional imaging of CT, is virtual autopsy which can enhance traditional autopsy or even replace it in some cases. 
Computed tomography (CT), as a widely available and a low invasive method, constitutes a routinely applied diagnostic tool in the diagnostic imaging of cranio-cerebral traumata. It allows detection of post-traumatic changes in the skull structure as well as demonstration of the extent of brain injuries and high density hemorrhagic foci even submillimeter size, in any planes. It also can detect site and source of bleeding or lesions requiring an immediate neurosurgical intervention which can protect the physicians from malpractice claims (Banaszek et al., 2010).

For the extent of our knowledge, the present study is the first study to report use of MDCT as a medicolegal evaluator in non-fatal firearm injuries in the head of in Upper Egypt population.

In this work, MDCT was done for the firearm injuries of the head. This is reported by Myint et al. (2014) and Magdy et al. (2008) who mentioned that the head/face were the most common sites of entrance. In addition the head region was the most preferred anatomical site by the assailants (Tingne et al., 2014):

The present study revealed that most of the injuries occurred in young aged males between 20-40 years.

This is in agreement with (Kohli and Aggarwal (2006) who mentioned that in India, the young age of most victims may be related to unemployed status which facilitates their willingness to engage in criminal activity, their aggressiveness by nature so they tend to provoke quarrels. Also males generally go to work outdoors and female tend to remain indoors. Males are also more exposed to daily stress activities. In addition, Solarino et al., (2007) mentioned that males are also more affected than females as they are expected to have the moral prestige of the family and any threat to it can lead to violence.

The role of cranial computed tomography (CT) in evaluation of firearm injuries to the head was investigated in conjunction to clinical examination in many studies (Martins et al., 2003 and de Santana Santos et al., 2011).

In the current study, MDCT showed features of inlet and exit wounds similar to clinical or forensic examination as regard site, shape, size, number and bone beveling. Additionally, it can help to determine direction and distance of firing.

It was reported that typical entrance wounds are ordinarily rounded in shape, may be surrounded by margin of abrasion in bullet injury, but they are oval with eccentric margin of abrasion in firing at an angle. Atypical inlets are irregular in shape and may have tears at the margins. They can be caused by defective weapon or ammunition, ricochet or passage of bullets through an intermediate target or contact firing over the skull. Inlets at near distance are surrounded by powder marks. Typical exit wounds can appear rounded, oval, slit like, stellate or crescent shaped. A typical appearance of exits when missiles push tissue or bone in front. Bullet penetration caused internal and external beveling of skull at the inlet and exit respectively (Denton et al., 2006).

The results of the present work showed that, weapons fire shots represented the highest percentage $(73.1 \%)$ while weapons fire bullets represented (26.9\%) of total cases. This can explain the higher percentage of inlets of small size which due to shots and the low percentage of inlets that have large size, which caused by bullet.

In agreement, the study of Abdel Hady et al. (2008) reported the pattern of firearm injuries and fatalities in Assiut Governorate, Egypt during the year 2006. The majority of victims were males who represented $86.31 \%$ of total cases and the mean peak age group was $20-30$ years $(31.25 \%)$ then $31-40$ years $(20.25 \%)$. The majority of injuries occurred from home made guns which represented $75.89 \%$ of totally used weapons of them $55.65 \%$ fire shots and $20.24 \%$ fire bullets. The long rifled weapons represented $21.43 \%$ and short rifled constituted only $2.68 \%$ of total cases.

The results of the present work revealed that, multiple inlet wounds present in $74.73 \%$ of total injuries while single inlet wounds represented $74.63 \%$ of total cases.

In agreement with the present study, the results of Mohamed et al. (2013) who studied the pattern of non-fatal firearm injuries in Quena governorate in years 2010 and 2011. The multiple injuries occurred in higher percentage $(57.6 \%)$ than single injury which represented $(42.4 \%)$ of total cases.

The CT can differentiate between various types of projectiles by their degree of fragmentation and bone destruction in tables of skull at the inlet and exit and soft-tissue destruction (von See et al. 2009). It was found that the skin entry wound locations derived from CT were identical to that seen clinically (Breeze et al. 2013).

In the current work, MDCT can help in determination of distance of firing. It was reported that MDCT can help to detect close-range firing by demonstrating the blackish soot or powder particles in the skin, singeing of the hairs around the entrance site, wads under the scalp or intracranial and dispersion of shots, (Große Perdekamp et al., 2013).

In accordance, the study of van Kan and Colleagues (2014) who compared the data of gunshot injuries in which both forensic radiological and forensic pathological examinations were done as regard the number and the tract of the projectiles. They found higher diagnostic value for radiology in determining a trajectory than forensic pathological examinations.

MDCT can differentiate between entrance and exit of the gunshot wounds in the head. MDCT scans allowed excellent documentation and storing of data of in situ conditions of the cerebral parenchyma revealed lanes of opaque bone and missile fragments along the course of the missile (Oehmichen et al., 2003). 
Open wounds to the head due to bullets pose special problems such as infection and have a high fatality rate as reported by Kaptigau et al. (2007). The craniocerebral firearm injury is a serious trauma and may associated with contamination and presence of retained intracranial projectiles (Wei et al., 2013).

MDCT is important for neuron-imaging, surgical planning and decision making to avoid the risk of infection, post traumatic epilepsy. It can clarify appearance of neurological findings, presence of intracranial projectiles, where their rapid removal is important in case management (Kazim et al., 2011 and Xing et al., 2015). Firearm injuries accompanied with disabilities or permanent infirmity or neurological findings can affect ability of victims to go back to their work. Good assessment of cases is important for compensations, determination of physician responsibility about complications of firearm injuries and

Existence of malpractice in the negligence claims (Tigerman et al., 2013).

In the current study, MDCT detect loss of vision due to either rupture globe or tear in the optic nerve. In agreement the study of Kükner et al. (2010) who mentioned that shots passing through the floor of the orbit often causes double perforation of the globe and once become in the orbital aperture, they travels towards the apex as a result of the conical shape of the orbit and lodge in the optic canal or severely damaging the optic nerve even if the globe is intact, so vision will be lost.

In agreement with results of the present study, the reports from studies that mentioned the role of MSCT in detection of permanent infirmity in non fatal firearm injuries such as parenchymal brain damage with neurological effects (Kazim et al., 2011), visual loss (Ahmadabadi et al., 2011 and Deyle et al., 2011) and Scolan et al., 2012), skull fractures (Viel et al., 2009), restricted mouth opening (de Oliveira et al., 2007), epilepsy (Kazim et al., 2011, Kendirli et al., 2014).

The MDCT findings is useful in the planning of brain neurosurgery in gunshot victims for prompt and successful treatment (Adolphs et al., 2013).

The percentage of permanent infirmities represented $8.9 \%$ of total cases (Abdel Hady et al., 2008).

The permanent infirmities occurred in $7.1 \%$ and $8.7 \%$ of non-fatal firearm injuries in Quena governorate in years 2010 and 2011 respectively (Mohamed et al., 2013). The permanent infirmity represented $4.1 \%$ and cure with complications occurred in $2.1 \%$ of total cases in firearm injuries in Suez Canal area from year 2005 to year 2010 (Hagras and Kharoshah, 2012).

In the present work, MDCT can help in demonstration of ante-mortem characters of firearm injuries such as air bubbles, hemorrhage and edema inside the cranium.

It was reported that the biometric reconstruction help to determine the angle of the missile track in all three planes in the zone of temporary cavitation and demonstrate the secondary changes as air bubbles along bullet course, hemorrhage and edema (Oehmichen et al. 2003).

In the current work, some cases showed retained whole bullets or their jacket between inner and outer table of skull, other cases showed migration of the bullet in the cranium or their rebound inside the cranial cavity.

In agreement with the present work was the study of Puentes et al., (2011) who reported that a cranial (3D-MDCT) revealed trapped multiple projectiles between inner and outer table of skull.

In harmony, the study of Rammo et al., (2012) who reported that some cases of firearm injuries to the head accompanied with spontaneous migration of these intracranial bullet fragments, with survival of the victims

In agreement, the study of Ibebuike et al., (2011) who stated that there's a possibility for intracranial rebound and swerving of the projectiles inside the skull. The bullet trajectory is not always straight; it depends on many cases including the status of the affected organs; the size, shape, initial speed of the bullet; the distance and direction of shooting

In this work MDCT can show intra-cranial finding such as neurological deficit due to loss of brain parenchyma by the fragmented bullet which was not seen by clinical or forensic examination. This was recorded by Kuchta and Klug (2009) who reported that clinical examination of man injured from a firearm weapon showed no neurological deficits, two bleeding bullet holes in skull bilaterally seen in the temporal areas initially suggesting a complete passage of a bullet through the head. Emergency CT showed two bullets hold inbetween the internal and external lamina of the temporal bone on both sides.

In this work, some cases demonstrated presence of cavitations inside the brain due to path of the missiles. In harmony, the study of Große Perdekamp et al. (2013) who stated that the CT can revealed cone-like cavitations along the bullet path as known from spherical missiles and penetration depths up to $25 \mathrm{~cm}$

In this study the presence of artifacts in the MDCT images were due to beam hardening effect. It was reported that artifacts may give difficulty to non experienced radiologists to obtain information about deformation and exact location of projectile in surrounding tissues. This can be minimized by use of cone-beam CT that allows radio-opaque objects to be localized (von See et al., 2009) and Stuehmer et al., 2011) 
Shaded surface display reconstruction for the entire gunshot-created complex skull fractures and brain injuries (such as wound channels and deeplydriven bone splinters) could be documented in complete and graphic detail. CT also documented vital reaction by demonstrating air emboli in blood vessels. Bullets and relevant histological samples from specific sites can be obtained via per-cutaneous biopsy guided with MDCT images in non-invasive fashion. As some cases of firearm injuries died later on from complications, the ante-mortem data of firearm injuries can be interpreted and subsequently correlated with the findings of classical autopsy (Thali et al. 2003).

MDCT allows in situ investigation of anatomic regions in fatal and non-fatal firearm injuries. It provides documentation in digital form (easily stored) which permits review by others and provides images that may be more suitable for presentation in court. As cases may died later, the MSCT has the potential to become a routine "virtual autopsy" tool in the future, it can give photos better than autopsy (Leth, 2009).

Forensic practitioners are becoming more reliant on MDCT images for identification, analysis, and evidence preservation. The digitally archived data can be re-consulted whenever new questions arise and can be sent to other experts for a second opinion (Stawicki et al, 2008). It allows re-examination of the victim and the crime scene even decades later (Bolliger et al., 2008).

The use of MDCT in evaluation of firearm injuries is valuable in difficult identification of persons either living or dead such as burning, mutilations and dismemberments where identification of injuries is a difficult task for the medicolegal experts (Fais et al., 2013).

\section{Conclusions and recommendations}

MDCT imaging is very valuable and non invasive diagnostic tool used in investigations of firearm injuries. Its images have many advantages as high resolution, thin thickness, three dimensions, multiple sections (16 raws), colored and accurate. It can shows injuries in soft tissues, bones and intra-cranial structures. MDCT can help in identification of the victims, differentiate between inlet and exit wounds, determine direction and distance of firing, showed any retained projectiles so help to determine type of used weapon. It can demonstrate presence of permanent infirmity. MDCT images are forensic evidence and represent easy storing of data enabled biometric reconstruction at any time, can be sent electronically for medicolegal consultant opinion and can be shown in the court so should be used in all medicolegal departments of Ministry of Justice.

Medicolegal physicians can depend on MDCT examination especially on difficult forensic examination of non-fatal and fatal firearm injuries such as in presence of burns, mutilations, putrefaction and obstacles in performing autopsy. It is important to make MicroCT should be available in Egypt, it gives details of gun powder residue in close and near distances.

\section{References}

Abdel Hady RH, Abdel Moneim WM and Abdel Aal KM (2008): Firearm injuries and fatalities. A preliminary study report in Assiut Governorate, Egypt in year 2006. Zagazig J. Forensic Med. Toxicol, 6 (1): 97-118.

Adolphs N, Liu W, Keeve E, et al. (2013): Craniomaxillofacial surgery planning based on 3D models derived from Cone-Beam CT data. Comput. Aided Surg.; May18(5-6):1018.

Agarwal S (2015): Trends and burden of firearmrelated hospitalizations in the United States across 2001-2011.Am J. Med. May;128(5):484-92.e1.

Ahmadabadi MN, Karkhaneh R, Valeshabad AK, et al., (2011): Clinical presentation and outcome of perforating ocular injuries due to $\mathrm{BB}$ guns: a case series. Injury. May;42(5):492-5.

Allareddy V, Nalliah R, Lee MK, et al. (2014): Impact of facial fractures and intracranial injuries on hospitalization outcomes following firearm injuries. JAMA Otolaryngol Head Neck Surg. Apr; 140(4):303-11.

Banaszek A, Guziński M and Marek Sąsiadek M (2010): Computed tomography angiography reveals the crime instrument - case report. Pol. J. Radiol. Apr-Jun; 75(2): 98-100.

Bolliger SA, Thali MJ, Ross S, et al., (2008): Virtual autopsy using imaging: bridging radiologic and forensic sciences. A review of the virtopsy and similar projects. Eur. Radiol; 18(2): 273-82.

Braga AA, Wintemute GJ, Pierce GL, et al. (2012): Interpreting the empirical evidence on illegal gun market dynamics. J. Urban Health. Oct; 89(5):779-93.

Breeze J, Leason J, Gibb I, et al. (2013): Computed tomography can improve the selection of fragment simulating projectiles from which to test future body armor materials. Mil Med. Jun;178(6):690-5.

Brough AL, Rutty GN, Black S, et al. (2012): Postmortem computed tomography and 3D imaging: anthropological applications for juvenile remains. Forensic Sci. Med. Pathol. Sep; 8 (3):270-9.

Colard T, Delannoy Y, Bresson F, et al. (2013): 3DMSCT imaging of bullet trajectory in 3D crime scene reconstruction: two case reports. Leg. Med. (Tokyo). ; 15(6): 318-22. 
Cecchetto G, Amagliani A, Giraudo C, et al. (2012): MicroCT detection of gunshot residue in fresh and decomposed firearm wounds. Int. J. Legal Med. May;126(3):377-83.

Cetin S, Eren B, Akan O, et al. (2013): An unusual case of firearm injury: bullet lodged in the tongue. Soud. Lek. Apr;58(2):31-2.

Denton J., Segovia A. and Filkins J. (2006): Practical pathology of gunshot wounds. Arch. Pathol. Lab. Med; 130: 1283-89

de Oliveira DM, Vasconcellos RJ, Laureano Filho JR, et al. (2007): Fracture of the coronoid and pterygoid processes by firearms: case report. Braz. Dent. J;18 (2): 168-70.

de Santana Santos T, Frota R, Martins-Filho PR, et al. (2011): Fracture of the coronoid process, sphenoid bone, zygoma and zygomatic arch after a firearm injury. J Craniofac Surg. Nov; 22(6):e34-7.

Deyle S, Exadaktylos AK, Kneubuehl BP, et al. (2011). Collateral Damage: Penetrating Head Injury and Orbital Injury, a Case Report. Am J Forensic Med. Pathol. ; 32 (3): 215-218.

Ebert LC, Ruder TD, Martinez RM, et al. (2015): Computer-assisted virtual autopsy using surgical navigation techniques. AJR Am. J. Roentgenol; 204 (1): W58-62.

Elserry T, Anwer $\mathrm{H}$ and Esene IN (2014): Image guided surgery in the management of craniocerebral gunshot injuries. Surg. Neurol. Int. Nov; 4(Suppl 6) :S448-54.

Fais P, Giraudo C, Boscolo-Berto R, et al. (2013): Micro-CT features of intermediate gunshot wounds severely damaged by fire. Int. J. Legal Med. Mar; 127(2):419-25.

Grabherr S, Doenz F, Steger B, et al. (2011): Multiphase post-mortem CT angiography: development of a standardized protocol. Int. J. Legal Med ; 125: 791-802.

Große Perdekamp M, Braunwarth R, Kromeier J, et al. (2013): Muzzle-loading weapons discharging spherical lead bullets: two case studies and experimental simulation using a skin-soap composite model. Int. J. Legal Med. Jul; 127(4):791-7.

Hagras AM and Kharoshah MA (2012): Medicolegal evaluation of firearm injuries during the period from 2005 to 2010 in the Suez Canal area, Egypt: A retrospective study. Egy. J. Forensic Sci., 2:1-10.

Ibebuike K, George B, Gopal R, et al. (2011): Spontaneous Intracranial Bullet Migration: A Complication of penetrating cranial gunshot wound: case report and review of the literature. J. Neurol. Sciences (Turkish); 28(4): 619-626.
Kaptigau WM, Ke L and Rosenfeld JV. (2007): Open depressed and penetrating skull fractures in Port Moresby General Hospital from 2003 to 2005. P N G Med J. Mar-Jun;50(1-2):58-63.

Kazim SF, Shamim MS, Tahir MZ et al. (2011): Management of penetrating brain injury. $\mathrm{J}$. Emerg. Trauma Shock. Jul-Sep; 4(3): 395402.

Kendirli MT, Rose DT and Bertram EH (2014): A model of posttraumatic epilepsy after penetrating brain injuries: effect of lesion size and metal fragments. Epilepsia. Dec;55(12):1969-77.

Kirkwood BR and Sterner JA (2003): Essential Medical Statistics, 2nd edition, Blackwell Science Inclusion, USA.

Kohli A and Aggarwal NK (2006): Firearm fatalities in Delhi, India. Leg Med (Tokyo). Oct;8(5):2648.

Kuchta J and Klug N (2009): Multiple cranial gunshot injuries without skull penetration. J. Forensic Leg. Med. Apr;16(3):159-61.

Kükner AS, Yilmaz T, Celebi S, et al. (2010): Characteristics of pellet injuries to the orbit. Ophthalmologica; 224:265-66.

Leth PM (2009): Computerized tomography used as a routine procedure at postmortem investigations. Am. J. Forensic Med. Pathol. Sep;30(3):219-22.

Magdy O, Kharosha A and Shotar A. (2008): Firearm fatalities in Dammam, Saudi Arabia. Med. Sci Law;48(3):237-40.

Manigandan T, Sumathy C, Elumalai M, et al. (2015): Forensic radiology in dentistry. J. Pharm. Bioallied Sci. Apr; 7(Suppl 1): S260-64.

Mohamed Z, Abdel Aal K, Mohamed I and Mohamed A (2013): Medicolegal evaluation of firearm injuries pattern (fatal and non fatal) in Quena governorate, Egypt during the years 2010 and 2011 (a retrospective Study). Ain shams J. Forensic Med. Clin. Toxicol. July ; 21:35-49.

Martins RS, Siqueira MG, and Santos MT (2003): Prognostic factors and treatment of penetrating gunshot wounds to the head. Surg Neurol. Aug;60(2):98-104.

Myint S, Rerkamnuaychoke B and Peonim V (2014): Fatal firearm injuries in autopsy cases at central Bangkok, Thailand: a 10-year retrospective study. J Forensic Leg. Med. Nov; 28:5-10.

Oehmichen M, Gehl HB, Meissner C, et al. (2003): Forensic pathological aspects of postmortem imaging of gunshot injury to the head: documentation and biometric data. Acta Neuropathol. Jun; 105 (6):570-80. 
Perandini S, Faccioli N, Zaccarella A, et al. (2010): The diagnostic contribution of CT volumetric rendering techniques in routine practice. Indian J. Radiol. Imaging; 20(2): 92-97.

Puentes K, Ribeiro C, Jardim P, et al. (2011): Non-fatal gunshot wounds in the context of intimate partner violence. The importance of a multidisciplinary approach: A case report. J. Forensic Leg. Med. July;18 (5): 221-24.

Puentes K, Taveira F, Madureira AJ, et al. (2009): Three-dimensional reconstitution of bullet trajectory in gunshot wounds: a case report. J. Forensic Leg. Med; 16(7):407-10.

Rammo RA, DeFazio MV and Bullock MR (2012): Management of migrating intracranial bullets: lessons learned from surviving an AK-47 bullet through the lateral brainstem. World Neurosurg. Mar-Apr;77(3-4):591.

Rapkiewicz AV, Shuman MJ and Hutchins KD (2014): Fatal wounds sustained from "falling bullets": maintaining a high index of suspicion in a forensic setting. J. Forensic Sci. Jan; 59 (1):268-70.

Reginelli A, Russo A, Maresca D, et al. (2015): Imaging assessment of gunshot wounds. Semin Ultrasound CT MR. Feb;36(1):57-67.

Sachan R, Kumar A and Verma A (2013): Frequency of Firearm Injuries, Deaths and Related Factors in Kanpur, India; an Original Study with Review of Literature. Int. J. Medical Toxicol. Forensic Med;3(3): 88-95.

Scolan V, Herry C, Carreta M, et al. (2012): Risks of non-lethal weapon use: case studies of three French victims of stinger grenades. Forensic Sci; Int; Nov :223(1-3):e18-21.

Shultz JM, Thoresen S, Flynn BW, et al. (2014): Multiple vantage points on the mental health effects of mass shootings. Curr. Psychiatry Rep. Sep; 16 (9):469

Solarino B, Nicoletti EM and Di Vella G (2007): Fatal firearm wounds: A retrospective study in Bari (Italy) between 1988 and 2003. Forensic Sci. Int; May; 168(2-3):95-101.

Stawicki SP, Gracias VH, Schrag SP, et al. (2008): The dead continue to teach the living: examining the role of computed tomography and magnetic resonance imaging in the setting of postmortem examinations. J. Surg Educ. ; 65: 200-205.

Stuehmer C, Blum KS, Kokemueller H, et al. (2011): Influence of different types of guns, projectiles, and propellants on patterns of injury to the viscerocranium. J. Oral Maxillofac. Surg. Apr;67(4):775-81
Tartaglione T, Filograna L, Roiati S, et al. (2012): Importance of 3D-CT imaging in single-bullet cranioencephalic gunshot wounds. Radiol Med; $\quad$ 117(3): 461-70.

Thali MJ, Yena K. and Vockb P. (2003): Imageguided virtual autopsy findings of gunshot victims performed with multi-slice computed tomography (MSCT) and magnetic resonance imaging (MRI) and subsequent correlation between radiology and autopsy findings. Forensic Sci. Int. Dec 17;138(1-3):8-16.

Tigerman M (2013): Guns, case management, and return to work. Prof Case Manag. NovDec;18(6):319-20.

Tingne CV, Shrigiriwar MB, Ghormade PS, et al. (2014): Quantitative analysis of injury characteristics in victims of interpersonal violence: an emergency department perspective. J. Forensic Leg. Med. Aug; 26:19-23.

van Kan RT, Kubat B, Haest IH, et al. (2014): Comparison between radiologist and pathologist in determining trajectories in gunshot victims. J. Forensic Radiol. Imaging, 2(2): 95-107.

Viel G, Gehl A and Sperhake JP (2009): Intersecting fractures of the skull and gunshot wounds. Case report and literature review. Forensic Sci. Med. Pathol.; 5(1):22-7.

von See C, Stuehmer A, Gellrich NC, et al. (2009): Wound ballistics of injuries caused by handguns with different types of projectiles. Mil. Med. Jul; 174(7): 757-61.

Weber GW (2001): Virtual anthropology (VA): a call for glasnost in paleoanthropology. Anat. Rec., 265 (4): 193-201.

Wei LF, Wang SS, Jing JJ, et al. (2013): Surgical therapy for cranio-cerebral firearm injury. Turk Neurosurg; 23(4):491-7

Weinberger SE, Hoyt DB, Lawrence HC, et al. (2015): Firearm-related injury and death in the United States: a call to action from 8 health professional organizations and the American Bar Association. Ann. Intern. Med. Apr; 162 (7):513-6.

Xing L, Duan Y, Zhu F, et al. (2015): Computed tomography navigation combined with endoscope guidance for the removal of projectiles in the maxillofacial area: a study of 24 patients. Int. J. Oral Maxillofac. Surg. Mar; $\quad 44 \quad$ (3): $\quad 322-8$. 


\section{الملخص العربحي}

\section{دور الأشعة المقطعية متعددة المقاطع فى التقييم الطبي الشرعي لإصابات الأعيرة النارية

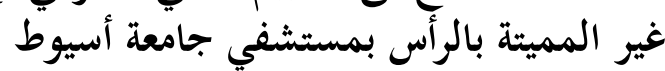

\section{خالد محمد عبد العال ا وحسام أبوزيا يوسف ومحمد زيدان محمدr}

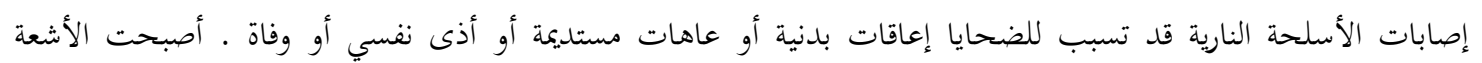

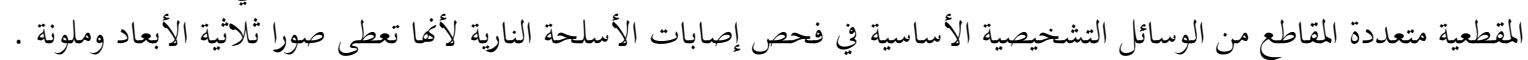

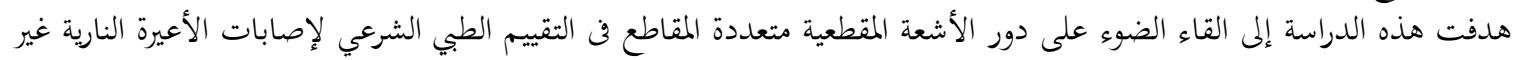

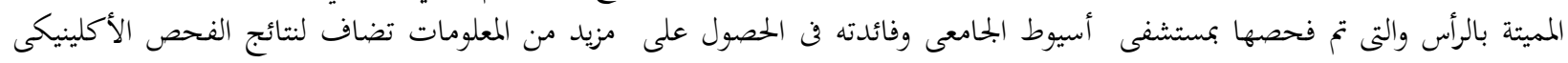
لتلك الحالات. أجريت الدراسة على سبعة وستين شخصا (· لج من الذكور و V من الإناث) من مصابى الأعيرة النارية غير المميتة بالرأس فن المرحلة

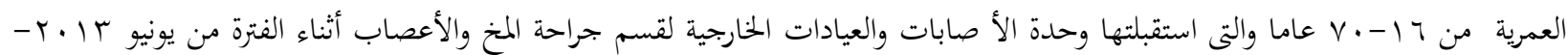

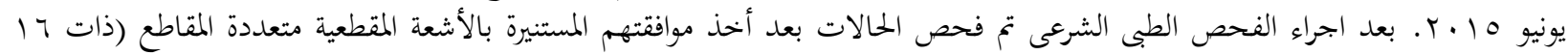

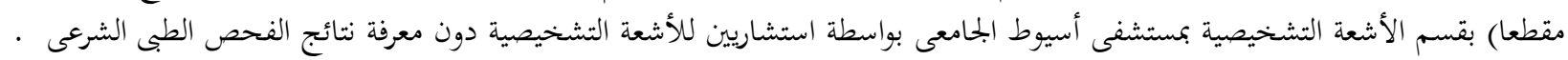

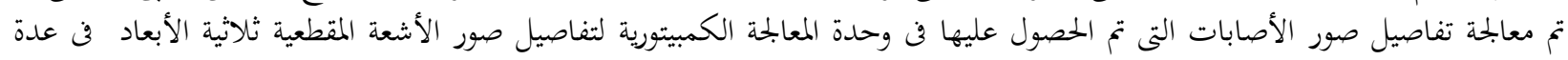

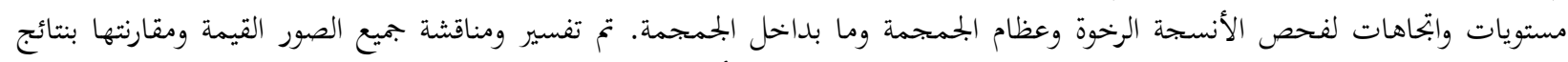

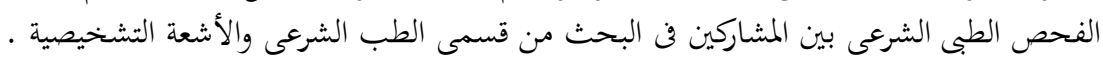

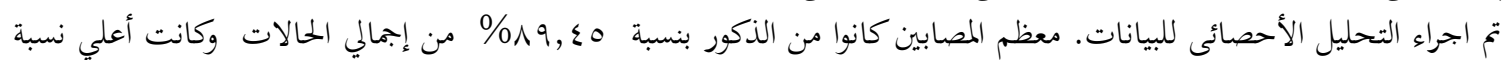

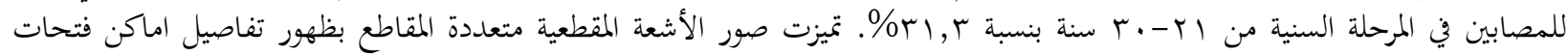

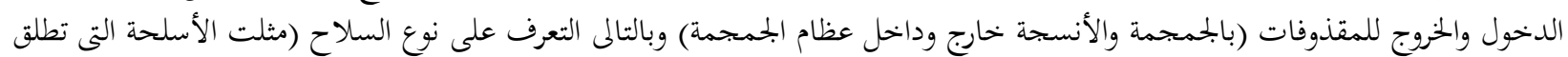

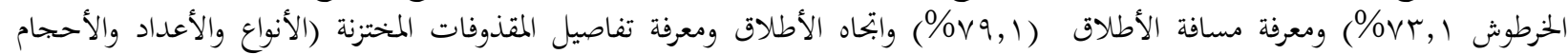

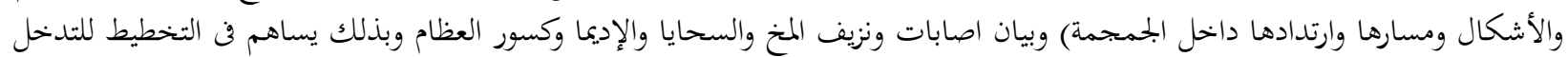

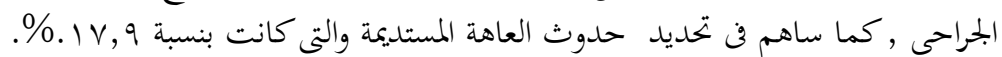

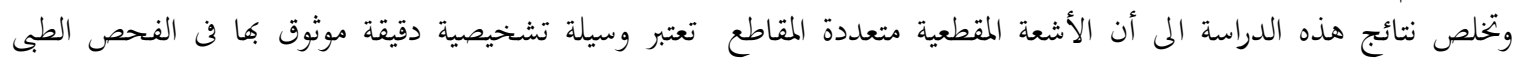

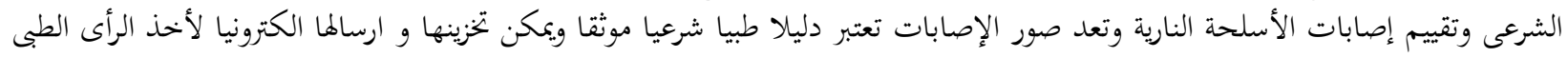

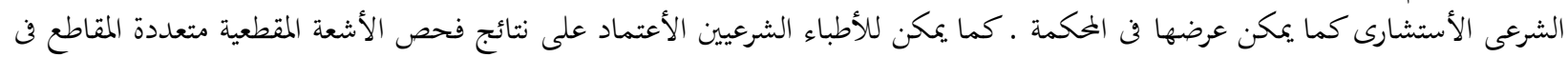

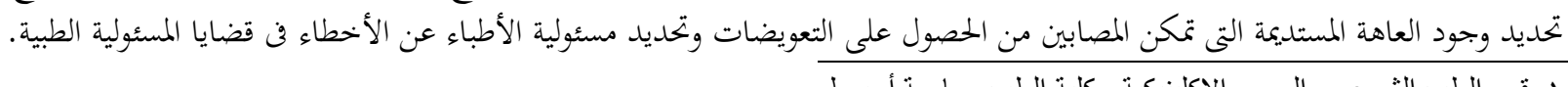

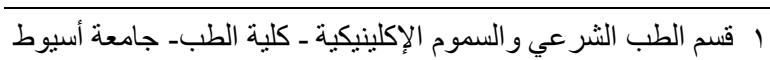

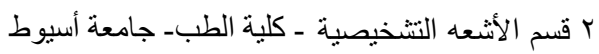

